

\title{
Technical Progress and Long-Run Growth
}

Chilosi, Alberto and Gomulka, Stanislaw

December 1969

Online at https://mpra.ub.uni-muenchen.de/17464/

MPRA Paper No. 17464, posted 22 Sep 2009 23:53 UTC 
by Alberto Chilosi

Congo State University

Stanislaw Gomulka

London School of Economics

\section{Technical Progress and Long-Run Growth}

Rivista di Politica Economica

SELECTED PAPER

FROM No. 3, 1969 


\section{Technical Progress and Long-Run Growth"}

\section{1. - Foreword.}

In this article the types of technical progress currently referred to in the theory of economic growtl will be passed in review and their relations studied in cletail. First the reciprocal relations of Hicks' and Harrod's classifications will be thoroughly examined. Secondly the various types of factor augmenting technical progress will be considered. Then Professor Kalecki's new classification of technical progress, as presented in his recent Theory of Growth of a Socialist Economy (1) will be taken into consideration; its overlapping with Harrod's classification will be shown. Light will also be shed on the dependence of the long-run rate of growth, in the presence of a constant rate of saving, on the type of technical progress taking place in the economy, both in the most general case and in that of an aggregate C.E.S. (Constant Elasticity of Substitution) production function; what happens in this respect in the case when technical progress is Harrod neutral is well known, the same cannot be said of the case when technical progress is not Harrod neutral.

(*) This work is based on a report submitted to Prof. Kalecki's seminar on the theory of econonic growth in Warsaw. February 1968. It appeared in Italian, in the June 1969 issue of our journal.

The paper constitutes a kind of survey of the theory of teclunical progress in which the arguments which were of most interest to seminar participants and where the authors were able to bring some personal contributions are most extensively treated. We apologize to the more specialized readers for having been a bit too long and detailed, particularly in the first paragraphs, in order to make the paper comprehensible to a larger audience.

(1) See M. Kalexkr: Zarys reorii wzrostu gospodarki socjalistycznej, sec. ed., Warsaw, 1968. 
The study will be carried out in the framework of the neoclassical aggregate model of economic growth. First we assume « malleable " capital, then we assume investment vintages, in order to make a comparison between the treatment of embodied and disembodied technical progress in western vintage models and in Kalecki's recent model of economic growth.

2. - Definitions and Assumptions. Hicks' and Harrod's Classifications.

For the present the investigation will be carried out in the framework of the neoclassical monosectoral model with malleable capital, which is characterized by the possibility to transform the existing capital stock in such a way as to adapt it instantaneously and without cost to changes in the relative factor endowments and to technical progress; consequently at a given moment a single production technique is used by the economic syslem as a whole. In view of the monosectoral nature of the model, all the magnitudes can be measured in physical units of the single good produced. Questions related to depreciation will not be considered; capital is supposed to last for ever.

The model is based on an aggregate production function:

$$
Y=F(K, L, l)
$$

where $Y$ stands for income, $L$ for labour, $K$ for capital and $t$ for time; the state of technique depends exclusively on the latter variable. The production function is strictly convex, continuous, differentiable at each point and homogeneous of the first degree with respect to $K$ and $L$. It is furtber assumed to possess those properties that make it "well behaved ", i.e.:

$$
\lim _{k \rightarrow \infty} f^{\prime}(k)=0 ; \quad \lim _{k \rightarrow 0} f^{\prime}(k)=\infty
$$

where $k \equiv K / L$ is the capital/labour ratio and $f(k)=F(K / L, 1, t)(2)$.

(2) See F. H. Hstin and R. C.O. MAThews: The Theory of Economic Growih: A Survey, "Economic Journal", Dec. 1964, n. 788. The meaning of these properties is discussed at length in A. CHrost: Cordizioni per l'esistenza della soluzione sabile e necessaria unicild di tale soluzione nel modello neoclassico monosetroriale, "Studi 
In our model the distinctive character of technical progress is provided by the fact that, as time passes, ever lower quantities of factors are needed to obtain a given quantity of product, or, alternatively, the quantity of product obtainable from given amounts of factors increases.

Given these assumptions, therefore, technical progress consists in a shift towards the origin of the coordinates (or towards the abscissae, according to the point of view) of the isoquants corresponding to given quantities of product.

Owing to constant returns to scale, for a given $t$ we have:

$$
Y=K F_{\kappa}+L F_{L}
$$

where $F_{K}$ and $F_{L}$ are respectively the marginal productivities of capital and of labour. Dividing both sides of [3] by $Y$ we get:

$$
U+Q=1
$$

where $U$ and $Q$ are respectively the partial elasticities of income with respect to capital and to labour; we shall from now on refer to them simply as factor elasticities or factor shares.

Let

$$
S \equiv F_{\mathrm{L}} / F_{\mathrm{K}}
$$

be the marginal rate of substitution. As is clear from [3] the fact that technical progress determines an increase in the quantity of product obtainable from given amounts of factors implies the increase over time of at least one of the marginal productivities. In the most general case, given the constancy of the amounts of factors available, the marginal rate of substitution will vary. If $S$ increases through time there will be technical progress that is labour-using and capital-saving according to Hicks' classification. In the opposite case there will be capital-using and labour-saving technical progress. If, on the other hand, $S$ remains unchanged, we have Hicks' neutral technical progress. Therefore, given the constancy of the amounts of the factors used, or, what amounts to the same thing [1] being linearly homogeneous, given the constancy of the ratio between the

di economia e finanza "; Pisa, 1966. See also \%. Okamoto and K. INada: A Note on the Theory of Economic Frowth, "Quarterly Journal of Economics", August 1962. 
amounts of the factors used (i.e. of $k$ ), capital-using technical progress increases $U$ (and reduces $Q$ ), while labour-using technical progress increases $Q$ (and reduces $U$ ) and neutral technical progress leaves $U$ and $Q$ unvaried. As the terms relating to the bias of technical progress will recur frequently in the present work, from now on we shall use the following symbols to save space: $P^{+}$for capitalusing technical progress, $P^{-}$for capital-saving technical progress and $P^{\circ}$ for neutral technical progress.

The above mentioned classification was formulated by Hicks in his Teory of Wages (3) to characterize the influence of technical progress on the distribution of income in a competitive economy. Later a different classification was proposed by Harrod. In the framework of the present model, Harrod's classification may be formulated as follows. If, given the constancy of $m \equiv K / Y$, the marginal productivity of capital increases (so that $U$ increases and $Q$ decreases), we have capital-using technical progress $\left(P^{+}\right)$, if it decreases (and therefore $U$ decreases) we have capital saving technical progress $\left(P^{-}\right)$, if it remains unchanged (so that both $U$ and $Q$ remain unchanged) we have neutral technical progress $\left(P^{\circ}\right)$.

In the case of $k$ remaining constant, the change in the factor elasticities depends exclusively on the action of technical progress (i.e. on the passing of time); if $k$ changes (as happens in the case of $m$ remaining constant, given the very nature of technical progress), the behaviour of factor elasticities depends on the combined action of two phenomena: a) technical progress and $b$ ) the substitution of one factor for another. Hicks' classification formalizes the first kind of action; on the other hand we may examine the effect that substitution has on the relative shares by resorting to the concept of elasticity of substitution. The latter, which we shall denote with $\sigma$, is defined, at a given point of the production function and at a given moment, as follows (4):

$$
\sigma=\operatorname{Lim}_{\Delta k \rightarrow 0} \frac{\Delta k}{k}-: \frac{\Delta S}{S}=\operatorname{Lim}_{\Delta k \rightarrow 0} \frac{\Delta k}{\Delta S} \cdot \frac{S}{k}
$$

(3) See J.R. Hicks: The Theory of Wages, London 1932, p. $121 \mathrm{ff}$.

(4) The elasticity of substitution is defined by $\mathrm{J}$. R. Hicks, op. cit., p. 117. It should be recalled that at a given point of the production function the elasticity of substitution of labour with respect to capital is equal to the elasticity of substitution of capital with respect to labour (see R. G. S. ALLEN: Mathematical Analysis for Economists, London, 1938, p. 341 foll.). 
Since the marginal rate of substitution is generally a function of $K$ and of $t$, namely $S=S(k, t)$, we may also write

$$
1 / \sigma=\frac{k}{S}\left(\frac{\partial S}{\partial k}\right)_{t} .
$$

Further reference will be made to [7] in Appendix II.

Two interrelated effects of technical progress can be distinguished: the first refers to its action on the marginal productivities of the factors at the various points of the production function, the second to its action on the elasticity of substitution at the various points of the production function (we have excluded a third possible effect, that of a change occurring in returns to scale, as we have assumed the linear homogeneity of the production function). As has been seen, the first effect is inherent in the very nature of technical progress; given the combination of factors, an increase in the marginal productivity of at least one factor derives directly from the definition of technical progress. However these two phenomena are closely interrelated; how the marginal productivities of the factors increase in relation to the various productive combinations depends strictly on the changes in the configuration of the isoquants, which are in turn responsible for changes in the elasticity of substitution. Incompatibility might therefore be supposed to exist between determinate biases of technical progress and determinate values of the elasticity of substitution. That this incompatibility does not exist is clearly demonstrated in Appendix I where, assuming a C.E.S. production function, the possibility is shown of having all three types of technical progress. according to both Harrod's definition and Hicks', irrespective of the value of $\sigma$.

\section{3. - Detailed Comparison of Hicks' and Harrod's Classifications.}

Let the curves shown in Fig. 1 be the isoquant corresponding to the production of a unit of income in two successive intervals of time. To see what the bias of technical progress is according to Hicks the two points $A$ and $B$ will be considered; to see what it is according to Harrod points $A$ and $C$ will be considered. In the latter case the result will be the same if one goes first from point $A$ to point $B$ and then from the latter to point $C$. In the first part 
of this path the factor elasticities change in relation to the bias of technical progress as formalized by Hicks. In the second part instead the change depends on the value of the elasticity of substitution in section $B C$.

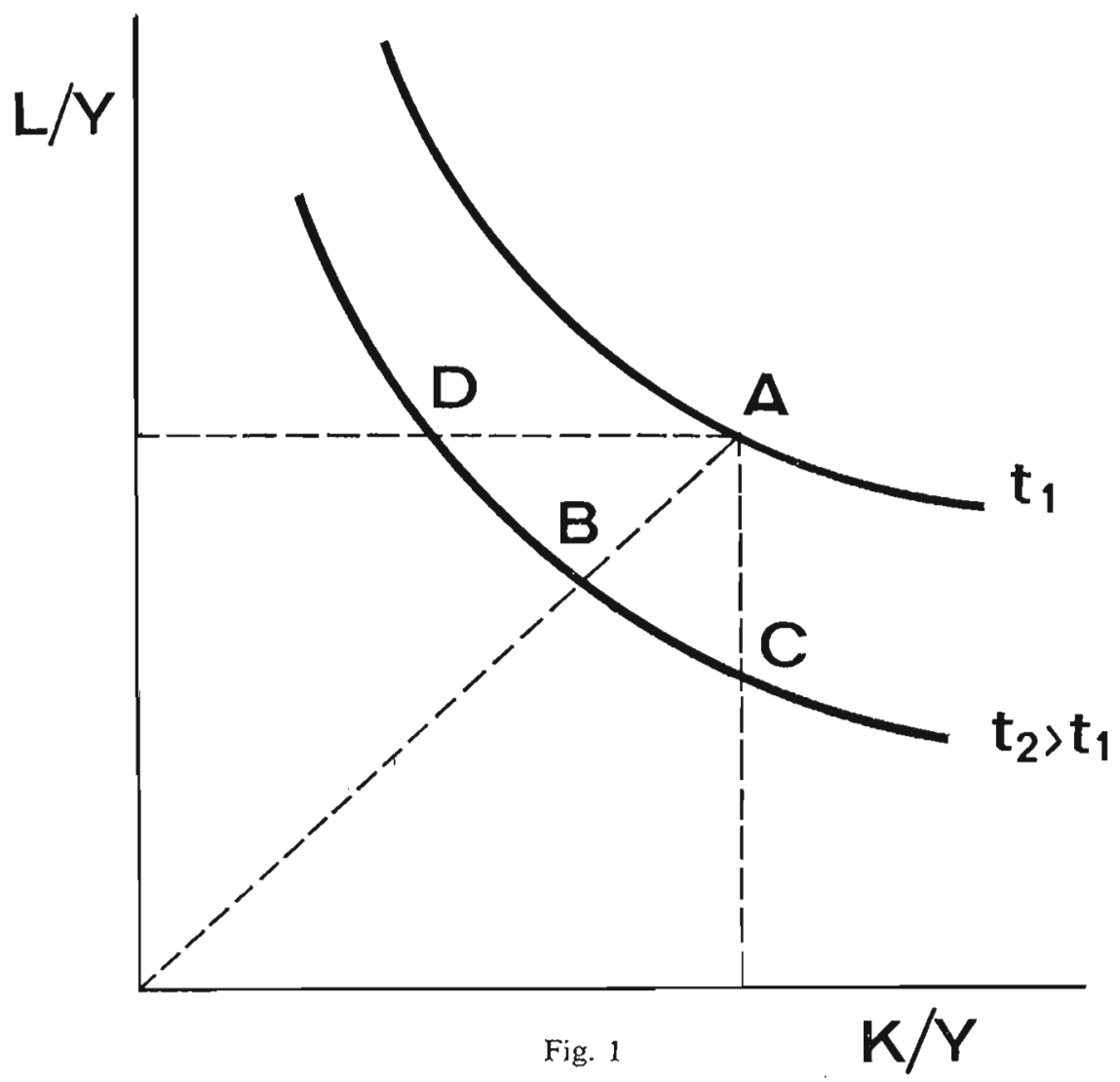

The value of the factor elasticities at point $C$, and therefore the bias of technical progress according to Harrod, will depend on the algebraic sum of the changes undergone by the factor elasticities in the two steps. These premises having been made, it is not difficult, by simple reasoning, to find the relationship between Hicks' classification and Harrod's, and vice versa, in relation to the value assumed by $\sigma(5)$. This relationship, the formal demonstration

(5) It must be borne in mind that, as can be interred by comparing [3] with [6], taking [5] into account also, and leaving technical progress aside, an elasticity of substitution equal to one makes the relative shares remain constant whatever 
of which will be found in Appendix II, is illustrated in the following table (6) (7):

T A B L. E 1

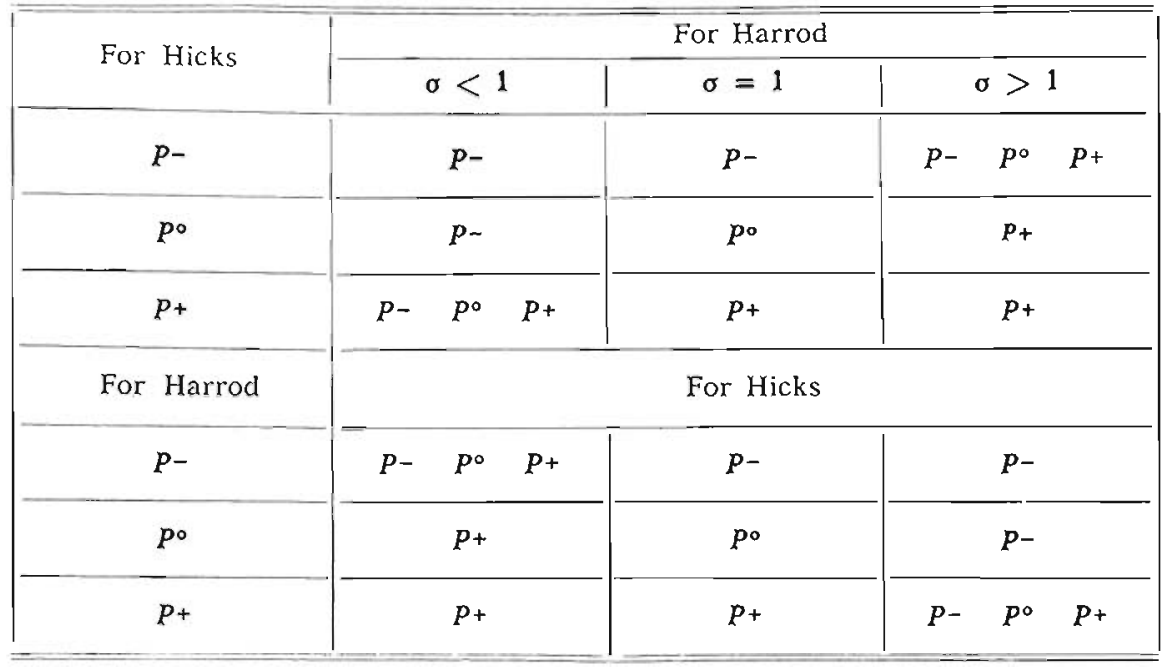

change occurs in the amounts of the factors employed in production. If the elasticity of substitution is higher than one the share of the factor that grows the most increases. On the other hand, if the elasticity of substitution is lower than one, it is the share of the factor that grows the least that increases.

(6) We give an example of the way the reasoning has to be conducted to arrive at the relations expounded in the table:

Suppose technical progress is Hicks capital saving and $\sigma<1$ : moving to the new isoquant by constant $k$ gives a higher labour share. Then moving along the isoquant to get the same capita!-output ratio as at the start gives a still higher labour share. Technical progress is therefore Harrod capital saving. The same conclusion can be reached if $\sigma=1$. If $\sigma>1$, on the other hand, in the first step the labour share increases, then decreases. The effect of technical progress and the substitution effect will be conlrasting and we cannot predict a priori which will be stronger. Technical progress will be accordingly capital saving, neutral or capital using for Harrod, in relation to the relative strength of the two effects. In the same way all the other relations in rable 1 can be found.

(7) The relationship existing between Harrod's and Hiciks' classifications was first studied by J. Robinson in The Classification of Inventions, "Review of Economic Studies", February 1938 (republished in Readings in the Theory of Income Distribution, London, 1950, p. 175 ff). In this work Mrs. Robinson shows to what bias Harrod's neutral technical progress corresponds, according to Hicks, in relation to the value of the elasticity of substitution. This subject was later taken up again bu Meade who, in his Nco-classical Theory of Economic Growth, London 1961, accepted Hicks' classification, extending it to the case of three factors of production. Meade show's (in Chapter VI, p. $55 \mathrm{ff}$.) the identity of Hicks' and Harrod's neutral technical progress in the case of unit elasticity of substitution. He also shows that Hicks' neutral technical progress is $p+$ for Harrod if the elasticity of substitution is higher than one. 
4. - The Long-run Path of Growth as Related to the Bias of Technical Progress According to Hicks' and Harrod's Classifications.

Differentiating [1] with respect to time we have:

$$
\dot{Y}=F_{\mathrm{K}} \dot{K}+F_{\mathrm{L}} \dot{L}+F_{\mathrm{t}} .
$$

Dividing both sides of [8] by $Y$ we get:

$$
r=U h+Q n+y,
$$

where $r$ is the rate of growth of income, $h$ the rate of growth of capital, $n$ the rate of growth of labour, and $y$ can be indicated as the rate of technical progress in Hicks' sense (8). From [9] it can be seen that the factor elasticities are the weights that determine the relative contributions made by the rates of growth of the factors to the rate of growth of income. The change of these elasticities through time is therefore of crucial importance for the determination of the path of growth.

At a given moment of time the values of $U$ and $Q$ depend on the capital-labour ratio and on the shape of the production function. But dynamically, through time, these values depend - as shown by equations [2.3] and [2.4] obtained in Appendix II - on the three following elements:

a) the rate of growth of the capital-labour ratio, $k / k=h-n$;

$b)$ the elasticity of substitution, $\sigma(t)$;

c) the intensity of the bias of technical progress, where the latter is defined as the growth rate of $S$, given a constant $k(9)$.

a) and $b$ ) have to be considered together: their joint effect may be termed effect of substitution.

c) on the other hand has a character of its own. The best thing is to consider it by resorting to Hicks' classification.

(8) See Meade: op. cit., Chapter I1.

(9) This definttion is given by J. C. H. FET and G. RANIS: Innovational Intensity aud Factor Bias in the Theory of Growth, "International Economic Review", May 1965. 
Let us now take into consideration equation [2.4], contained in Appendix II:

$$
\dot{U} / U=(1-U)\left[\frac{\sigma-1}{\sigma} \frac{\dot{k}}{k}-\frac{1}{S}\left(\frac{\partial S}{\partial t}\right)_{k}\right] .
$$

In this equation the effect of substitution is indicated by the first component of the expression between square brackets. If the capitallabour ratio changes, this effect differs from zero only in the case of $\sigma \neq 1$. The sign and the absolute value of the second component depend, on the other hand, on the bias of technical progress (according to Hicks) and on its intensity. With [10] we have succeeded in showing clearly how the effect of substitution and the intensity of the bias of technical progress act on the growth process through their effects on factor elasticities. What still has to be clarified in [9] is what the value of $y$ depends on. Differentiating both sides of [3] with respect to time and assuming the constancy of $K$ and $L$, we get:

$$
y=\frac{1}{Y} \frac{\partial Y}{\partial t}=U b+Q c,
$$

where $b=\frac{1}{F_{\mathrm{K}}} \frac{\partial F_{\mathrm{K}}}{\partial t}$ and $c=\frac{1}{F_{\mathrm{L}}} \frac{\partial F_{\mathrm{L}}}{\partial t}$ are functions of $k$ and $t$.

On the other hand it follows from the definition of $S$ that

$$
\frac{1}{S}\left(\frac{\partial S}{\partial t}\right)=c-b
$$

Given a certain initial value of $k$ and $m$, the value of $n$ (which given the assumption of full employment is determined exogenously) and a given value of the rate of saving $s$, the path of growth will be determined by the dynamics of $U$ and of the two variables $b$ and $c$. If the impact of the bias of technical progress on the value of $I J$ is in keeping with the substitution effect, it will be easy to find the value that the rates of growth of income and of capital assume in the long run. The two following cases may occur: 1) $\sigma>1$ and $p^{\circ}$ or $P^{+}$(in Hicks' sense; i.e.: $c \leqslant b$ ). In conformity with [6] $U$ 
grows as time passes (10). We shall denote the long-run values of the variables (i.e. when $t \rightarrow \infty$ ) by placing the sign + above on the right. Thus if $\sigma>1, U^{+}=1, Q^{+}=0$. In the long run, therefore, the rate of growth of income tends to be equal to $h+b$. The rate of growth of capital being lower than the rate of growth of income, the former increases in time, bringing about an unlimited increase in the rate of growth. Since, by hypothesis, $\dot{K} / Y \equiv s$ is constant, the rate of growth of $h$ is equal to $r-h$ and therefore, at the limit, for $t=+\infty$ it is equal to $b^{*}$. As a result if $b^{+}>0, r^{+}=+\infty$ and $h^{+}=+\infty$.

The same will happen in the case of $\sigma=1$, given bias $P^{+}$.

2) $\sigma<1$ and $P$ or $P^{\circ}$ (i.e. $c \supseteq b$ ). If it is assumed that $\sigma^{+}<1$, then $U^{+}=1$ and $Q^{+}=Q$. As a result $r^{+}=n+c^{+}=h^{+}$. The same is obtained in the case of $\sigma=1$ and bias $P$.

3) $\sigma=1$ and $P^{\circ}$. [6] shows that $U$ (and therefore also $Q$ ) is then independent of changes in the capital/labour ratio. Since here $b=c$, according to [11] $y=b=c$ and therefore

$$
r=U h+Q n+b,
$$

for any time $t$ and in particular for $t=+\infty$. It can easily be shown that $r^{+}=h^{+}$. Let us in fact assume that in [13] we have $r>h$. Then $K / Y \equiv m$ decreases and $h=s / m$ increases (we always assume $t$. $s$ is constant). Given the constancy of $U, Q, n$ and $c$, therefore, $r$ increases too. But $r$ increases less than $h$ inasmuch as $r=U h+$ constant, where $U<1$. Hence $(h-r)$ decreases, tending towards zero. If $r=h, m$ is constant and we have golden age growth. The following result can therefore be reached:

$$
r^{+}=h^{+}=c / Q+n=\alpha+n
$$

where $\alpha$ is the rate of growth of labour productivity, taking into account that in [13] $U=1-Q$. The same holds if one starts from

(10) It should be taken into account that in the long run always $h>n$ and therefore $\frac{\dot{k}}{k}>0$. This may be deduced from [9], taking into account [3], and from the fact that, given the assumed constancy of $s, \frac{\dot{h}}{h}=r-h$. (Footnote (5)
should also be recalled). 
an initial situation in which $r<h$. From this it can be concluded that, in the case considered, the golden age rate of growth, $r^{+}=$ $=c / Q+n$, is stable $(11)$.

If the effect of technical progress and the effect of substitution are contrasting, i.e. in the case of $\sigma<1$ and $P^{+}$, and $\sigma>1$ and $P^{-}$, it is not possible to determine a priori the trend of the long-run rates of growth of income and of capital. All growth paths are possible, among others those of types 1), 2) and 3).

On the other hand, if one considers Harrod's classification, it is possible to identify a priori the long run path of growth only if tecnical progress is neutral. In discussing this case the following relation obtained in Appendix II will be helpful:

$$
\frac{\dot{U}}{U}=\frac{\sigma-1}{\sigma} \frac{\dot{m}}{m}+\frac{1}{U}\left(\frac{\partial U}{\partial t}\right)_{m} .
$$

The first component of the right-hand side of [15] is the quantitative expression of what may be indicated as the effect of substitution in Harrod's sense; the second component may be indicated in turn as the measure of the intensity of technical progress, also in Harrod's sense. Consequently, if Harrod's $P^{-}$is accompanied by $\sigma>1$, the effect of technical progress and the effect of substitution are constrasting, provided $\dot{m} / m>0$. As can be seen in Table I, in this case Harrod's $P^{-}$technical progress is also Hicks' $P^{-}$. The same happens, mutatis mutandis, in the case of $P^{+}$and $\sigma<1$. Thus the long-run rates of growth of income and of capital are not determinable a priori inasmuch as they depend on the concrete values of $\sigma(t)$ and on the intensity of bias $P^{-}$, or $P^{+}$.

On the other hand, in the case of Harrod's $P^{+}$accompanied by $\sigma>1$ and $P^{-}$accompanied by $\sigma<1$, it might appear at first sight that the economy tends in the long run to set on growth paths 1) and 2) respectively. This is not certain, however, except in the case in which the rate of capital growth always exceeds the rate of income growth. The fact is that for $h>r$ (and therefore in [15] $\dot{m} / m>0$ ) the effect of substitution acts in conformity with the corresponding bias of technical progress, while, for $h>r$ it acts in the opposite

(11) See R.M. Solow: A Contribution to the Theory of Economic Growth, "Quarterly Journal of Economics", February 1956; T. Swav: Economic Growth and Capital Accumulation, "Economic Record ", November 1956; MEADE, op. cit., Chapter IV. We shall later refer to this result as the "theorem of convergence". 
sense. In these cases, in effect, non-neutral technical progress in Harrod's sense may correspond to any bias in Hicks' sense, even that which, accompanied by a corresponding value of the elasticity of substitution, makes the path of long-run growth unidentifiable a priori.

In the case of Harrod's $P^{\circ}$ accompanied by $\sigma=1$, technical progress is neutral also in Hicks' sense (see Table I); the path of long-run growth is therefore characterized by a golden age rate of growth equal to $\alpha+n$.

Let us further suppose that $\sigma \neq 1$. Then Harrod's $P^{\circ}$ corresponds to Hicks' $P^{-}$if $\sigma>1$ and to $P^{+}$if $\sigma<1$. In both cases, if capital grows at the same rate as income, factor elasticities do not change and we have a golden age rate of growth. On the other hand, if capital grows at a higher (lower) rate than income, the rate of capital growth decreases (increases). So that in this case there are good reasons to suppose that the path of long-run growth is of type $c$ ). In our model this will always be the case, as we have assumed the properties of the production function corresponding to equations [2]: the necessity of convergence towards the golden age path is in fact linked to the assumption of these two properties (12).

We have anyhow reached the conclusion that in the case of a contrasting action of technical progress according to Hicks and of the effect of substitution, a golden age path of growth is possible.

On the other hand, according to a widely shared opinion, if technical progress is not Harrod's $P^{\circ}$ golden age growth is not possible. A distinctive feature of the golden age is in fact the equality of the rates of growth of income and capital and, as a consequence, the constancy of the capital/output ratio corresponding to a constant level of the aggregate rate of saving and a constant level of factor elasticities. But in the case of Harrod's non-neutral technical progress if, by hypothesis, $m$ is constant, the factor elasticities change. Further (as follows from [9]), in the presence of a constant value of $s$ the value of the difference $r-h$ must also in general change and therefore, contrary to the hypothesis, the capital/output ratio must change too (13). It should however be noted that a state of

(12) See A. Chilosi, op. cit.

(13) See HAHN and MatrHews, op. cit., p. 829. On the same page the authors write: "Labour-saving bias in technical progress... tends on most assumptions to cause the rate of increase of output to grow over time. Likewise capital-saving bias 
growth characterized by the constancy of $m$ and of $s$ in the presence of Harrod's non-neutral technical progress appears possible from [9] if, during the growth process, the changes in $U$ and in $Q$ are exactly compensated by corresponding changes in $y$ so as not to have any influence on the rate of growth.

\section{5. - Factor-Augmenting Types of Technical Progress.}

Only in the case of Harrod's $P^{\circ}$ at each point of the production function there can be an infinity of logarithmically parallel golden ages, characterized by the same growth rate of income, capital, and efficiency labour (for an explanation of this expression see below, pp. 17-18). This is due to the fact that only in this case (as we shall show in par. 6) does the rate of growth of labour productivity in correspondence to a constant value of the capital/output ratio not depend on the level of this ratio. In this case the production function can be be written as follows:

$$
Y=F(K, A L)
$$

where $A$ is an increasing function of time (14). It follows directly from this equation that technical progress of this kind has the same productive effects as an increase in employment proceeding at the same rate at which $A$ grows (15). That is why this kind of technical progress is called labour- augmenting. In referring to it we shall, for the sake of brevity, use the sign $P_{\text {LA }}$.

If we take $\alpha$ to denote the rate of growth of $\mathrm{A}(t)$, we get from [16]

$$
r=U h+Q(\alpha+n) .
$$

The identity of the productive effect of technical progress and of the growth of labour is clearly shown in [17] (note that both $\alpha$ and $n$ are exogenous variables). From [12] it follows that in the case

tends to deceleration.... (our italics). We hope to have made it clear which assumptions determine the accuracy of these conclusions.

(14) See H. Uzawa: Neutral Inventions and the Stability of Growth Equilibrium, * Review of Economic Studies", February 1961.

(15) This was pointed out for the first time by J. RoBInson, op. cit. 
of golden age growth, in which $h=r, \alpha=r-n$; namely $\alpha$ is equal to the rate of growth of labour productivity.

If the production function is of the Cobb-Douglas type (namely if $\sigma=1$ ), it then follows from [16] that the value of $Q$ does not depend on the level of $k$ and does not change when changes occur in the value of the capital/labour ratio.

Since, by hypothesis, $\alpha$ is in [17] a function of time only, like $A$ in [16], the value of $y$ (see [9]), which in this case is equal to $\alpha Q$, is independent of the value of $k$. On the other hand, if the production function is not of the Cobb-Douglas type, $Q$ depends on the level of $k$ and, in the case of Harrod's $P^{\circ}$, therefore, the value of $y$ changes at the various levels of $k$ as a consequence of the changes in $Q$ (it must be always taken into account that $y=\alpha Q$ and that $\alpha$ does not depend on the level of $k$ ).

The concept of capital-augmenting technical progress, briefly $P_{C A}$, can be introduced in the same way. The rate of this progress, equal to $y / U$, has the same effect, as regards the rate of growth of income, as an increase in capital stock taking place at the same rate. The $P_{C_{A}}$ bias may be defined (analogously to Harrod's definition of the $P_{\mathrm{LA}}$ bias) as requiring the constancy of the marginal productivity of labour, given the constancy of its average. productivity (16). In this case $r=n$ and, the factor elasticities remaining constant, the average productivity of capital (i.e. the reciprocal of the capital/output ratio) must grow at the same rate as its marginal productivity, i.e. at the $y / U$ rate. But this kind of neutrality of $P_{C A}$ technical progress is only apparent. In the $P_{1 . \wedge}$ case in effect the economy tends, if the rate of investment is constant, to bring about a state of balanced growth in which factor elasticities do not change. In the $P_{C A}$ case this is only possible when the elasticity of substitution is one, namely in the case of a production function of the Cobb-Douglas type. In fact, if income increases at a constant rate resulting from the sum of a constant rate of technical progress $y / Q=\alpha$ and of a constant rate of labour growth. $n$, capital grows at the same rate as income. As has been seen, this is the fundamental characteristic of the golden age. But in this case the rate of

(16) For this definition see HahN and Matthews, op. cil., p. 830; E. S. Phelps: Axioms for Factor Augmenting Technical Progress, Cowles Foundation Discussion paper N. 196, October 1965, p. 3; R. Sato and M. J. BeckmanN: Neutral Inventions and Production Functions, "Review of Economic Studies", January 1968, p. 59. 
growth of capital evidently cannot be equal to the rate of growth of labour. Hence the average productivity of labour cannot be constant. Therefore if we have $P_{\mathrm{CA}}, U$ and $Q$ can be constant only if the elasticity of substitution is equal to one. Then neither technical progress nor substitution tend to change the values of factor elasticities, which therefore remain constant.

The $P_{\mathrm{CA}}$ bias is then alternatively Harrod's $P^{-}, P^{\circ}$ or $P^{+}$according to whether the elasticity of substitution is lower than, equal to, or higher than one. We can use fig. 1 to show this.

Passing from point $A$ to point $D$ the factor elasticities do not change. To see what the bias of technical progress is for Harrod, we pass from point $D$ to point $C$. If in the interval $C D \sigma=1$, the factor elasticities do not change in passing from $D$ to $C$ and we have Harrod's neutral technical progress. If $\sigma>1$, in passing from $D$ to $C U$ increases and we have Harrod's $P^{+}$, if $\sigma<1, U$ decreases and we have Harrod's $P^{-}$. The same holds for Hicks' classification, passing from point $D$ to point $B$.

Thus, just as technical progress of type $P_{\mathrm{LA}}$ can be inserted into the production function by means of a multiplicative factor of physical labour, increasing function of time, $P_{\mathrm{CA}}$ technical progress can be inserted into the production function by means of a multiplicative factor of capital, increasing function of time (17). In both cases we can choose the productive effect of a certain dated quantity of capital or labour as an unit for measuring capital or labuur, respectively, in efficiency units (18). In the case of $P_{\text {LA, }}$ the rate of growth of income and capital in the golden age is equal to the rate

(17) The importance of this kind of technological progress lies in the fact that it (and it alone) allows the aggregation of the capital stock in efficiency units and the construction of a global production function for the economy as a whole also in the case in which capital is not assumed to be "malleable". See in this respect R.M. Solow: Technical Progress, Capital Formation and Economic Growth, "American Economic Review" (Papers and Proceedings), Miay 1963, p. 56 ff. and also F.M. FISHER: Embodied Technical Change and the Existence of an Aggregate Capital Stock, "Review of Economic Studies " October 1965; ID.: Embodied Technology and the Aggregation of Fixed and Movable Capital Goods, "Review of Economic Studies" October 1968. The relations between capital augmenting and Hicks and Harrod neutral and biased technical progress are stated by JosSA: Teoria economica del progresso tecnico, Milano, Giutïrè, 1966, p. 259 fl.

(18) " an efficiency unit of capital or labour is that amount which is a perfect substitute of a standard unit produced or performed in a given base period" (H.A. Green: Embodied Progress Investment and Growth, "Anerican Economic Review ", March 1966, p. 150). 
of growth of labour in efficiency units. In the case of $P_{C A}$, on the other hand, the rate of growth of income is given by

$$
y=U(\beta+h)+Q n,
$$

where $\beta$ is the rate of growth of the capital-augmenting factor, i.e. the rate at which the average and marginal productivities of capital increase, given the constancy of the average (and at the same time the marginal) productivity of labour.

In the particular case of Hicks' $P^{\circ}$, there is no change in the shape of the isoquant, but only an increase at the same rate of the productive effects of both factors. Technical progress can then be characterized merely by an increase in the level of output corresponding to the different isoquants of the production function; the latter may therefore be written as multiplied by an increasing function of time (19):

$$
Y=F(K, L) C(t)
$$

In this case technical progress can be said to be prociuct augmenting.

Differentiating [19], the rate of growth of income comes to be expressed as follows:

$$
r=U h+Q n+\gamma
$$

where $\gamma$, the rate of growth of $C$, does not depend on the level of $k$ and is only a function of time.

The following production function includes the various possible cases of factor-augmenting technical progress:

$$
Y=F[B(t) K, A(t) L]
$$

In view of the linear homogeneity of [21], the laticr may also be written

$$
Y=B(t) F\left(K, \frac{A(t)}{B(t)} L\right)
$$

(19) See Solow: A Contribution, op. cit., p. 85; Uzawa, op. cit., p. 120. 
Or, in the case of $A(t)$ and $B(t)$ growing at constant rates, given initial condition $A(0)=B(0)=1$ :

$$
Y=e^{\beta 1} F\left(K, e^{(\alpha-\beta) t} L\right)
$$

Factor augmenting technical progress (briefly $P_{\mathrm{FA}}$ ) is therefore a combination of Hicks' $P^{\circ}$ at rate $\beta$ and of Harrod's $P^{\circ}$ at rate $\alpha-\beta(20)$. It is therefore clear that the $P_{F A}$ type of technical progress, in its various possible specifications, is of a rather special kind (21). It should be observed, for example, that if technical progress is of the $P_{F A}$ type and $\sigma=1$, technical progress must respond to Hicks' criterion of neutrality, although, in the case of $\sigma=1$, technical progress generally can very well be non-neutral in Hicks' sense. This because, in case $\sigma=1$, the production function is of the CobbDouglas type and if, for instance, there is $P_{c_{A}}$ technical progress, this progress is also $P_{\mathrm{LA}}$ and Hicks' $P^{\circ}$, and vice versa.

It should be noted that if one wishes to consider the bias of factor-augmenting technical progress according to Hicks' classification, this bias is seen to be determined by the value of Harrod's neutral element (i.e. if $\alpha \geq \beta$ ) and by the value of $\sigma$. If $\alpha>\beta$ we shall find that for $\sigma>0$ technical progress will be Hicks' $P^{-}$and for $\sigma<0 P^{+}$(see Table I). The reverse will be true in the case of $\beta>\alpha(22)$.

The bias according to Harrod may be determined analogously i.e. by considering Hicks' neutral component and the value of $\sigma$.

(20) See VANek: Towards a More General Theory, op. cit.; M. J. BeckMann: Einkommensverteilung und Wachsium bei nichtneutraiem technischen Forschritts, "Jahrbücher für Nationalokonomie und Statistik", 1965, p. 81) ff. (These two papers are concerned with the determination of the long-run path of growth in the case of factor-augmenting technical progress); Saro and BECKMAr.i, op. cit., p. 57.

(21) Phelps (Axioms, op cit., p. 6 ff.) shows that technical progress can be described as factor augmenting if, and only if, "at time $t$ the rate of change of the capital-output ratio necessary to keep shares constant is independent of the capital-output ratio ". Another description of factor-augmenting technical progress is provided by $\mathrm{S}_{\mathrm{A} T O}$ and BLCKMANN (op. cit., p. 63). They show that technical progress can be described as factor augmenting if the elasticity of substitution remains constant when factor shares are constant.

(22) See Phelps, Axioms, op. cit. 
Differentiating [21] we get the following expression for the rate of growth:

$$
r=U(\beta+h)+Q(\alpha+n)
$$

In this case we have

$$
y=U \beta+Q \alpha .
$$

Comparing [25] with [11] one might be inclined to conclude that the former is a particular case of the latter that occurs when $b$ and $c$ of [11] (which correspond to $\beta$ and $\alpha$ of [25]) are only functions of time and do not in any way depend on the value of $m$ and $k$. However it is not so. In can be shown in fact that in the case of factor-augmenting technical progress $b$ and $c$ take the following form (23):

$$
\begin{aligned}
& b=\frac{\partial F_{\mathrm{K}}}{\partial t} \quad \frac{1}{F_{\mathrm{K}}}=\beta-\frac{Q}{\sigma} \quad(\beta-\alpha) ; \\
& c=\frac{\partial F_{\mathrm{L}}}{\partial t} \quad \frac{1}{F_{\mathrm{L}}}=\dot{\alpha}+\frac{U}{\sigma}(\beta-\alpha) .
\end{aligned}
$$

Substituting [26] and [27] in [11] we obtain [25] (24).

\section{6. - Kalecki's Classification of Technical Progress; Its Relation with Harrod's Classification.}

So far we have considered classifications and characterizations of determinate types of technical progress that have been worked out and used in the West, usually to study the impact of technical change and growth on the relative shares of factors in the framework of a competitive economy. Owing to their technological basis, however, these classifications are of general value since they can be used in any growth model, irrespective of its institutional specifi-

(23) See Phelps, Axioms, cit., pp. 10-11; B. Jossa: Analisi ecoroinica del progresso tecnico, Milano 1966, pp. 120-125.

(24) For a survey of the various possible iypes of "neutrat "technical progress in relation to the various possible meanings of the term, including some not considered by us, see SaTo and BECKMANN, op. cit. 
cations. Professor Kalecki, on the other hand, has recently formulated a new classification of technical progress that is strictly related to the planner's decisional process in a socialist economy. The planner has to decide the level of the share of accumulation in the national income and the level of the capital coefficient to be chosen for the new investment projects. These decisions will be influenced by various considerations, which are related to the implications of the choices to be made. The study of the logic of these choices is the object of Kalecki's recent book, Outline of the Theory of Growth of a Socialist Ernnomy.

Of particular importance among the implications of the planner's decisions are those related to the effects of the bias of technical progress and of the level of the capital coefficient on the rate of growth of labour productivity. In short, the planner will choose a higher aggregate rate of saving and a higher capital coefficient for future investments when the rate of growth of labour productivity is a positive function of the level of the capital coefficient. And conversely in the opposite case.

Kalecki consequently divides technical progress into " encouraging capital intensity ", "discouraging capital intensity " and neutral, according to whether the rate of growth of labour productivity at a constant level of the capital coefficient is positively related, inversely related, or unrelated to the level of the capital coefficient (25).

We shall now show that Kalecki's classification of technical progress, although different in its formulation, corresponds exactly to Harrod's classification (26). For the sake of brevity we shall use the same symbols for Kalecki's classification as for Hicks' and Harrod's, namely $P^{+}, P^{-}$and $P^{\circ}$ respectively for the three types of technical progress mentioned above.

Kalecki considers an economy with vintage capital; this is an aspect of his model we shall return to later. For the time being it will be sufficient to point out that in a model of this kind the concepts of production function and technical progress, in the: sense used so far, apply only to the ex ante production function.

(25) KaLECKI, op cit., p. $70 \mathrm{ff}$.

(26) An alternative proof, considering, as in Mrs. Robinson article of 1938, the shift of the curve of the average productivity of capital, as a result of technical progress, by a given quantity of labour, will be found in Appendix III. 
The character of the model insofar as it concerns ex post substitutability, however, is of no importance as far as the nature of the classification of the bias of technical progress is concerned. Kalecki's classification can therefore be examined within the limits of the model in the rramework of which we have worked so far. Alternatively, if the reader prefers, what we are going to say can be applied to the ex ante production function and [1] may now be considered to represent this function. In his book, however, Kalecki does not work explicitly with the production function, but instead starts from the assumption that a relation exists between labour productivity, $w \equiv Y / L$, and the level of the capital coefficient, $m \equiv K / Y$.

Kalecki describes this relationship graphically by means of the isoquant (which he calls curve of production) corresponding to the production of a unit of income (27). Since the "curve of production $\gg$ is assumed to be falling and convex everywhere, the relationship between labour productivity and the capital coefficient is one to one and can be expressed in the form of a function. This relationship can therefore be written:

$$
w=f(n, t) .
$$

It follows from [28], moreover, that the implicitly assumed production function connecting income with factor endowments is homogeneous of first degree. Only in this case, in fact, is the productivity of labour a function of the capital coefficient, irrespect. ive of the scale of production.

[28] can be obtained from [1] as follows:

Given the linear homogeneity of [1] we have:

$$
Y=L F(K / L, 1 ; t)=L F(m w, 1 ; t)
$$

or, dividing by $L$ :

$$
w=F(m w, 1 ; t)
$$

In view of the assumed one to one character of the relationship connecting $w$ with $m,[30]$ can be solved in such a way as to obtain $w$ as an explicit function of $m$, as expressed in [28].

(27) KILECKI, op. cir., p. $66 \mathrm{ff}$. 
At the starting point $t=0$ we know the graph representing $w^{\circ}(m)=f(m, 0)$, i.e. the relationship existing between labour productivity and the capital coefficient.

Kalecki assumes that, for any given value of $m$, we know the value of the rate of growth of labour productivity that occurs when $m$ is maintained at a constant level. In other words we know the function

$$
\alpha^{0}(m, t)=\frac{1}{w}-\frac{\partial w}{\partial t}
$$

Kalecki's classification of the bias of technical progress is based on the nature of the dependence of $\alpha^{\circ}$ on $m$; when $\frac{\partial \alpha^{\circ}}{\partial m} \equiv \alpha^{\circ}{ }_{\mathrm{m}}>0$ technical progress is $P^{+}$, when $\alpha_{\mathrm{m}}^{\circ}<0$ it is $P^{-}$and when $\alpha_{\mathrm{m}}^{\circ}=0$ it is neutral. Integrating [31] we are ablo to put the productivity of s.r... $w$ in an explicit relation with $m$ and $t$, given the values of $w^{\circ}(m)$ and of $\alpha^{\circ}$ :

$$
w=f(m, t)=w^{\circ}(m) \exp \int_{0}^{t} \alpha^{\circ}\left(m, t^{\prime}\right) d t^{\prime}
$$

Let us now calculate the rate of growth of labour productivity, $\dot{w} / w=\alpha$. This rate may differ from $\alpha^{\circ}$ as $m$ is not necessarily constant in time. Considering [28] we have: $\dot{w}=f_{m} \dot{m}+f_{t}$.

From [32] we know that $f_{m}=w_{n 1}^{o} \frac{w}{w^{\circ}}+w \int^{t} \alpha_{m}^{o} d t^{\prime}$ and therefore

$$
u=\left(\frac{1}{w^{\circ}} w^{\circ}{ }_{m}+\int_{0}^{t} \alpha_{m}^{o} d t^{\prime}\right) \dot{m}+\alpha^{o}=q \frac{\dot{m}}{m}+\alpha^{\circ},
$$

where $q / m$ stands for the expression between the brackets (28). In view of the definition of $w$ and $m$, moreover, we know that $a=$ $=r-n$ and $\dot{m} / m=h-r$. By substituting these expressions in [38] we can obtain a general expression for the rate of growth,

(28) Since $\dot{w} / w=u=\frac{1}{w}-\frac{\partial w}{\partial m} \dot{m}+u^{\circ}$, it follows from the comparison with [33] that $q=\frac{m}{w} \frac{\partial w}{\partial m}$, namely that $q$ is the elasticity of labour productivity with respect to the capital/output ratio. 
placing at the same time in relief the influence of the bias of technical progress in Kalecki's sense on the value of this rate:

$$
r=\frac{q}{1+q} h+\frac{1}{1+q} n+\frac{\alpha^{\mathrm{o}}}{1+q} .
$$

In addition to this expression for $r$ we also have the preceding one, consisting of [9], already known to us. Both these relations must be satisfied simultaneously, irrespective of the magnitude of the rate of growth of labour and of the rate of growth of capital. For this to occur, the coefficients by which $h$ and $u$ are multiplied and the last component of the right-hand sides of the two equations must be equal. It ensues that

$$
U=\frac{q}{1+q}=m F_{\mathrm{K}}
$$

[35] gives the key enabling us to relate Kalecki's classification to Harrod's. According to Kalecki, technical progress is $P^{+}$when $\alpha_{\mathrm{m}}^{\circ}>0$. From the definition of $q$ we know that in this case, given the value of $m$, the expression $\mathrm{q}(m, t)$ increases in time. The quotient $\frac{q}{1+q}$ then increases at the same rate and so, as follows from [35], does the marginal productivity of capital: technical progress is then $P^{+}$also in Harrod's sense. In the case of $\alpha^{\circ}<0$, the expression $q(m, t)$ decreases as time passes and consequently $\frac{q}{1+q}$ and $F_{\mathrm{K}}$ decrease too. Agreement exists between Kalecki's classification and Harrod's also in this case. Finally, if $\alpha_{m}^{\circ}=0$, with $m$ constant, also $q(m, t)$ is constant and therefore we have from [35] that $F_{\mathrm{K}}$ is constant, too. Technical progress is then neutral both for Harrod and for Kalecki.

With the help of [35] it is easy to verify that the equivalence is satisfied also in the opposite case, starting from Harrod's instead from Kalecki's classification.

Up to now we have worked with a model in which capital is technically homogeneous. Its productive properties do not depend, at a given moment of time, on the date of its production. The first 
to depart from this unrealistic assumption was Leif Johansen in 1959 (29).

Whereas in the original neo-classical model with malleable capital technical progress acts indifferently on the whole production apparatus irrespective of the date of construction, in Johansen's model technical progress is embodied in the successive vintages of capital goods. Once a determinate vintage of capital goods has been installed, its productive capacities do not change up to the moment of its scrapping. On the other hand technical progress can be considered to be partly embodied and partly disembodied; Johansen's original model has since been altered, so as to take this possibility into account (30). Kalecki's model is also of vintage type and is characterized by the presence of two types of technical progress that correspond to a considerable extent to the division made, in certain western models with investment vintages, between embodied and disembodied technical progress. In Kalecki's treatment there are, however, some interesting peculiarities to which, among other things, the next two paragraphs will be devoted.

\section{7. - Technical Progress in Vintage Models.}

Each part of the capital stock of the whole economy (machinery, equipement, plants etc.) can be ranged according to the time of its construction. In the period from $v$ to $v+d v$ a quantity $I_{v} d v$ of new capital goods is produced in the old plants. At moment $t$, where $t \supseteq v, L_{\mathrm{v} t}$ workers are employed with these capital goods. Let us continue to assume, as we have done so far, that there is no period of gestation in production and that capital can last indefinitely without becoming worn out. We shall also continue to assume that only one good is produced; the model continues to be mono-sectoral. This good, however, though its qualities remain unaltercd if it is used for consumption purposes, changes its productive qualities as time passes if it is used as a capital goud.

(29) L. Johansen: Substitution versus Fixed Production Coefficients in the Theory of Economic Growth: A Synthesis, "Econometrica", April 1959.

(30) See in particular E. SHESHINSKr: Balanced Growth and Stability in the Johansen Vintage Model, "Review of Economic Studies", April 1967. 
All the innovations at the current time $t$ can be divided into the following groups:

1) A group that we shall denote with $v^{*}$. The innovations belonging to this group are absorbed exclusively by the most recent vintage, i.e. by vintage $v=t$. These innovations have all the effects we have so far connected with technical progress; namely they bring about an increase in the output that can be obtained from a given amount of factors.

2) A group we shall denote with $t^{*}$. To this group belong the innovations contemporarily absorbed by all the vintages. Here the economic effects of the innovations are not related to the formation of a vintage that embodies them, but are spread uniformily over the whole productive apparatus, inclusive of the most recent vintage, which also absorbs the innovations of type $v^{*}$.

Whereas the latter logically include improvements of a technological as well as organizational nature, the innovations of type $t$ refer mainly to organizational improvements in the economy as a whole.

In the following pages we shall limit ourselves to examining the working of vintage models in a state of steady growth and with labour augmenting technical progress.

The $v^{*}$ innovations present at moment $v$ insure efficiency labour at moment $v$ being equal, in vintage $v$, to $A_{v} L_{\mathrm{v}}$, where $A_{v}$ is a function of $v$ increasing at rate $\alpha$. Moreover, if the existence of disembodied technical progress is also assumed, $t$ innovations bring the quantity of labour in efficiency units, combined with investment vintage $v$, at moment $t \geqslant v$, to the level

$$
L_{\mathrm{vt}}^{*}=B_{\mathrm{v}} A_{\mathrm{v}} L_{\mathrm{v} t}
$$

where $B_{\mathrm{t}}$ is a function of current time $t$, increasing at rate $\gamma$. Assuming that both kinds of technical progress jointly augment efficiency labour, the income produced by vintage $v$ at time $t$ is

$$
Y_{\mathrm{vt}}=F\left(I_{\mathrm{v}}, e^{\alpha \mathrm{v}+\gamma^{t}} L_{\mathrm{v}}\right) \text {, where } t \geqslant v \text { and } B_{0} A_{0}=1 .
$$

In the above equation, however, $L_{\mathrm{vt}}$ cannot be arbitrary for $t>v$. It may in fact be assumed either: $a$ ) that the production coefficients can be changed a posteriori or $b$ ) that they cannot. 
If the latter assumption is made, the ex post fixity of coefficients can be specified in one of the following two ways (31): 1) by assuming the ex post constancy of the capital/labour ratio, measuring labour in efficiency units; 2) by assuming this ratio to be constant, but measuring labour in physical terms. The difference between these two interpretations of the fixity of the capital/labour ratio is that the first implies that employment in physical terms must decrease in the old vintages at rate $\gamma$ i.e. the rate at which disembodied technical progress proceeds, and that the income produced by the various vintages of the capital stock does not change through time from the moment of their installation. If the second interpretation is adopted, on the other hand, employment in physical terms remains unchanged in the old vintages, while labour in efficiency units grows at rate $\gamma$, and consequently the income produced by each vintage of the capital stock increases. Thus $Y_{\nabla t}$ increases at rate

$$
u=\mu \gamma,
$$

where $\mu$ is the elasticity of output with respect to efficiency labour in the ex ante production function. (In golden age growth $\mu$ will have the same value for all vintages). It should be noted that, once the investments corresponding to vintage $v$ have been completed, an increase in employment in efficiency units generates an increase in income only if it occurs as a consequence of technical progress. As this does not seem very logical, the first interpretation is to be preferred.

If the possibility of ex post changes in production coefficients is assumed, several solutions are possible. The ex post flexibility of coefficients may be assumed following the original ex ante preduction function (32). In this case [36] and [37] are applicable. Or, more realistically, a particular (ex post) utilization function, different from the ex ante production function at the time of the con-

(31) See Seshinski, cit., p. 240.

(32) For models in which this assumption is made (together with the assumption: of a Cobb-Douglas production function and of capital augmenting technical progress in order that the hypothesis of the existence of embodied technical progress be consistent with the possibility of having an aggregate production function for the economy as a whole) see R.M. Solow: Capital Theory, cit., p. $56 \mathrm{ff}$; Technical Progress, Capital Formation and Economic Growth, cit., as well as E. Prelps: The New View of Investment, "Quarterly Journal of Economics", November 1962. 
struction of the plants may be assumed. In particular it may be supposed:

a) that output increases proportionally to employment (this may be measured in efficiency units) until a certain capital/efficiency labour ratio is reached beyond which an increase in employment can no longer cause an increase in output (linear utilization function) (33);

b) that the productivity of efficiency labour decreases as the quantity employed with a given vintage increases; this utilization function, a particular case of which occurs when it is identical with the original ex ante production function, need not necessarily be equal to it.

On the other hand there is no reason why, unlike the ex ante production function, the utilization function should not, for instance, provide increasing returns to scale (34).

In the case of both a posteriori substitutability and fixed production coefficients, the problem exists, in the models we are considering, of the efficient distribution of the available labour among the various vintages and of the choice of the optimal capital/labour ratio in the new vintage by a given level of the rate of saving; this is a problem that occurs specifically with regard to the optimal combination of capital intensity in the new vintage and intensity of renewal of the old vintages. If, as we are supposing, the economy is in a state of steady growth, this problem is assumed to have already been solved, either by the market mechanism of a perfectly competitive economy or, alternatively, by the «benevolent planner ". As a result the capital/efficiency-labour ratio of successive vintages at the time of their construction is identical for all of them and the economic life of all vintages is constant (35).

In any case the increase of income in the period from $t$ to $t+d t$ is equal to the difference between the production of the new

(33) This assumption is made by C.J. Br.sss On Putty-Clay "Review of Economic Studies ", April 1968, p. 106.

(34) Ibidem, pp. 106-107.

(35) This has been shown in all models with embodied technical progress written after Johansen's original work. In the latter, in fact, the problem of obsolescence and of the determination of the economic life of capital goods in relation to the efficient distribution of the available labour force among the various vintages of the capital stock was not taken into consideration. 
vintage, $Y_{\mathrm{tt}} d t$, and that of the vintage that is being scrapped $Y_{\mathrm{tt}-\mathrm{T} \mathrm{t}}$ (here $T$ is the life of capital goods, which is a constant in a golden age), plus the sum of the increases in income that may occur as a result of an increase of efficiency labour combined with the other vintages (these increases can even be negative if employment in efficiency units decreases, as in most cases it should). Each of these increases is proportional to $Y_{v t}$ with the coefficient of proportionality $u_{v}$. If all the $u_{v}$ 's are identical ard equal to $u$, the sum of the single increases of the various vintages is proportionate to the sum of the single $Y_{\mathrm{vt}}$ 's, i.e. to $Y_{\imath}$ with the coefficient of proportionality $u$. We therefore have:

$$
Y_{\mathrm{t}}=Y_{\mathrm{t}, \mathrm{t}}-Y_{\mathrm{t}-\mathrm{T}, \mathrm{l}}+u Y_{\mathrm{t}}
$$

As always $r$ denotes the rate of growth of income. Fur growin to take place along a steady path, investments $I_{v}$ must grow at the rate $r$, i.e. $I_{\mathrm{v}}=I_{0} e^{\mathrm{rv}}$. The rate of growth of labour is $n$. Taking [36] into account we have

$$
\begin{gathered}
Y_{\mathrm{t}, \mathrm{t}}-Y_{\mathrm{t}-\mathrm{T}, \mathrm{t}}=F\left(I_{0} e^{\mathrm{rt}}, e^{(\alpha+\mathrm{n}+\gamma) t} L_{0}\right)- \\
-F\left(I_{0} e^{\mathrm{r}(\mathrm{t}-\mathrm{T})}, e^{(\alpha+\mathrm{n}+\gamma)(\mathrm{t}-\mathrm{T})+\varepsilon \mathrm{T}} L_{0}\right),
\end{gathered}
$$

where $\varepsilon$ denotes the rate of growth of labour in the successive vintages after the time of their installation (37). This difference grows at a constant rate only when

$$
r=\alpha+n+\gamma \text {. }
$$

In fact the difference $Y_{\mathrm{t}, \mathrm{t}}-Y_{\mathrm{t}-\mathrm{r}, \mathrm{t}}=\left[F\left(I_{0}, L_{0}\right)-F\left(I_{0} e^{-\mathrm{rT}}, \mathrm{L}_{0}\right.\right.$ $\left.\left.e^{\mathrm{T}\left(\varepsilon^{-}-r\right)}\right)\right] e^{\mathrm{rt}}$ increases at rate $r$ as the expression in square brackets does not depend on current time $t$. As a result, in this case, we have both sides in [39] growing at the same rate $r=\alpha+\beta+\gamma$, constant through time.

(36) This equation is equivalent to the one found in KaLECKI, op. cit., p. 23.

(37) $\varepsilon$ is usally null or negative according to the assumptions made in the various models. 


\section{8. - The Treatment of Innovations in Kalecki's Model.}

Kalecki too divides the innovations absorbed by the economic system in two groups:

1) Group $v^{\prime}$, which includes innovations both of technological and organizational nature absorbed by the latest vintage $v=t$. If the capital coefficient is constant, their absorption brings about an increase of labour productivity in the new vintage as compared with the preceding ones (38).

2) Group $t^{\prime}$, which comprises mainly innovations of an organizational nature, absorbed by vintages $v<t$, namely by those vintages already existing at time $t$ (39).

It is easy to see that this division is not exclusive; there may well be innovations that are contemporarily of type $v^{\prime}$ and type $t^{\prime}$.

On the contrary, in models of the kind considered in the preceding paragraph, the sets $v^{*}$ and $t^{*}$ are mutually exclusive; a glance at their definition is sufficient to prove this. This is a first difference between the two divisions.

The second difference is that it seems logical that innovations of more various kind can be included in the sum of sets $v^{\prime}$ and $t^{\prime}$ than in the sum $v^{\prime \prime}+t^{\prime \prime}$; all the innovations that can be included in the first subdivision can be included in the second, but the contrary is not true.

In addition to this difference in the division of innovations there are differences in Kalecki's model with regard to the effect of each group on the growth of the economy (principally as a consequence of the difference mentioned above). Given the constancy of the capital coefficient $m_{\mathrm{v}}=I_{\mathrm{v}} / Y_{\mathrm{vv}}$, the absorption of innovations of type $v^{\prime}$ leads to an increase in labour productivity in vintage $v=t$ as compared with all the pre-existing vintages, at a rate that generally depends (as we have seen in par. 6) on the level of $m$. As we have shown in par. 6 , the classification of technical progress for

(38) KaLECKI, op. cit., p. 33.

(39) Ibidem, pp. 22-23. This seems the kind of technological progicis :nentioned by N. KAL.DOR and J.A. MiRRLEes in: A New Model of Economic Growth, "Review of Economic Studies", 1961-62 (Vol. XXIV), p. 176: "it is probable that in addition to " embodied " technical progress there is some "disembodied "technical progress as well, resulting from increasing know-how in the use of existing rnachilux ". 
this group of innovations corresponds exactly to Harrod's. Assuming technical progress to be neutral, and considering for the time being only innovations of type $v^{\prime}$, the flow of income produced by vintage $v$ at time $t$ will be equal to

$$
Y_{\mathrm{vt}}=F\left(I_{\mathrm{v}}, e^{\alpha v} L_{\mathrm{v}}\right), \quad v \leq t .
$$

In models of the kind considered in the preceding paragraph the quantity of labour in efficiency units employed with vintage $v=t$ is $L_{\mathrm{v}}{ }^{*}=e^{\left(\alpha^{+} \gamma\right)_{v}} L_{\mathrm{v}}$, whereas in Kalecki's model $L^{*}=e^{\alpha v} L_{\mathrm{v}}$. Therefore in models of the first kind the sum $\alpha+\gamma$ corresponds to $\alpha$ in Kalecki's model.

For vintage $v=t$ the effect of the absorption of innovations of type $v^{\prime}$ is exactly the same as the aggregate effect of the absorption of the innovations $v^{*}$ and $t^{*}$.

The innovations $t^{\prime}$ (as well as the innovations $v^{\prime}$ at the time of the "birth" of these vintages, i.e. at time $v$ ) have an additional effect on the production of vintages $v<t$. Kalecki assumes that, in the case of labour $L_{\mathrm{vt}}$ increasing at a constant rate $\beta$, which can also be negative or null, income $Y_{\mathrm{v} t}$ increases at a constant rate $u$, independently of the bias of technical progress (40).

From this point of view the productive effect of the absorption of innovations $t^{\prime}$ corresponds to that resulting from the absorption of type $t^{*}$ innovations in the preceding paragraph, in the particular case for which [37] holds; in both cases production increases in the lifetime of vintage $v$ at a constant rate $u$.

The consideration of the absorption of innovations $t^{\prime}$ calls for a change in equation [41]. It is possible to check that Kalecki's abovementioned assumptions are always respected, regardless of the bias of technical progress, when

$$
Y_{\mathrm{v} t}=F\left(e^{\mathrm{u}(\mathrm{t}-\mathrm{v})} \quad I_{\mathrm{v}}, e^{(\mathrm{u}-\xi)(\mathrm{t}-\mathrm{v})+\alpha \mathrm{v}} L_{\mathrm{v} \mathrm{t}}\right) .
$$

In effect, since we have $L^{\mathrm{vt}}=L_{\mathrm{vv}} e^{\beta(t-v)}$, and $F$ is supposed to be homogeneous of the first degree, we get from [42] that

$$
Y_{\mathrm{vt}}=F\left(I_{\mathrm{v}}, e^{\alpha v} L_{\mathrm{vv}}\right) e^{\mathrm{u}(\mathrm{l}-\mathrm{v})},
$$

(40) See Kalecki, op. cit., pp. 36-37. 
that is $Y_{v_{t}}$ increases at rate $u$. From [41] it would appear that through time the technical progress linked to the absorption of innovations $t$ augments both factors of production in each $v<t$ vintage: labour $L_{\mathrm{vt}}$ at rate $\mu-\beta$ and capital $I_{\mathrm{v}}$ at rate $u$.

This is not however a necessary condition for steady growth to be possible (41). If, for instance, the quantity of capital in efficiency units increases at the constant rate $\gamma_{1}$ and the quantity of labour in efficiency units at the constant rate $\beta+\gamma_{2}$ in vintagc $v$, income $Y_{v t}$ increases at rate

$$
u=(1-\mu) \gamma_{1}+\mu\left(\gamma_{2}+\beta\right)
$$

which is constant if the elasticity $\mu$ is assumed to be constant through time and returns to scale are constant in the utilization function. Parameters $\gamma_{1}$ and $\gamma_{2}$ are arbitrary constants. It may happen, in particular, that $\gamma_{1}=0$ and $\gamma_{2}=\gamma$. We then have

$$
u=\mu(\gamma+\beta)
$$

namely, in the case $\beta=0$, a relation formally identical to equation [37].

In any case, if production in the old plants increases at the constant rate $u$ and employment at the cunstant rate $\varepsilon$, the possibility of having steady growth exists. In fact [39] takes the following form:

$$
\begin{gathered}
Y_{\mathrm{t}}-Y_{\mathrm{t}-\mathrm{T}, \mathrm{t}}=F\left(I_{0} e^{\mathrm{rt},} e^{(\alpha+n) t} L_{0}\right)- \\
-e^{\mathrm{uT}} F\left(I_{0} e^{r(\mathrm{t}-\mathrm{T})}, L_{0} e^{(\alpha+n)(\mathrm{t}-\mathrm{T}) \cdot \varepsilon \mathrm{T}}\right) ;
\end{gathered}
$$

and it is easy to ascertain that this difference increases at a constant rate when $r=\alpha+n$.

We may therefore come to the following conclusions: a) The distinction made by Kalecki between technical piogiess that acts on the ex ante production function and technical progress that acts on the existing vintages of the capital stock makes the condition for the existence of steady growth, in so far as it concerns the

(41) The working of his model in a state af steady growth and the assun!ptions that make this state possible are considered by KALECKI in chapter III of his book. 
latter type of technical progress, that labour productivity and employment must be able to increase at constant rates in the existing vintages of the capital stock. $b$ ) In all vintage models, whatever their specific characteristics may be, the rate of steady growth (in which $m=$ constant, $s=$ constant and $r=$ constant) in the economy as a whole is equal to the sum of the rates of growth of employment and of labour productivity in the new vintage.

\section{9. - Technical Progress, Steady Growth and Long-run Growth in Vin- tage Models.}

In most cases there will be the possibility of steady growth only if technical progress shifting the ex ante production. funrtion is Harrod's and Kalecki's neutral; the reasons for this are of the same kind as we have taken into consideration for models with malleable capital. On the other hand, even if technical progress absorbed by the old vintages of the capital stock is not labour augmenting, there may be steady growth, as we have seen in the preceding paragraph. Moreover the possibility exists of having steady growth also with non-neutral technical progress in the ex ante production function, in the particilar case described at the end of paragraph 4 (42).

So far as concerns the relationship between the bias of technical progress and long-run growth in the case of vintage models, it is most probably of the same type as in models with malleable capital. What has been said in the preceeding paragraphs for the case of malleable capital may be extended to the new vintage of vintage models. As, in the long run, the path of growth along which the economic system proceeds is traced by the successive new vintages, while the old vintages gradually disappear or lose their relative importance, as compared with the bulk of the more recent

(42) This is denied by C. J. Buss who (op. cit., pp. 110-111) gives a formal proof that steady growth (or balanced growth, as he calls it) is only possible if we have Harrod's neutral technical progress. In his proof Bliss does not take into account tha fact that, if the rate of labour augmentation changes when $m$ changes, we have not Harrod's neutral technical progress, even if the tom of the production function is $Y=F(K, A L)$, where $A=A(m, t)=A_{0} \exp \alpha^{0}(m) t$, as is shown in par. 6 of the present article. 
ones, the relationship between types of technical progress (with regard to the new vintage) and the path of economic growth must logically be the same in models with vintage capital as in those with malleable capital. However an accurate treatment of this problem in a vintage model involves far from negligible mathematical difficulties; and does not seem to lead to the discovery of new results, interesting enough to justify the task of overcoming these difficulties (43).

\section{0. - The Level of Technology as an Endogenous Variable.}

Since the present paper has in some respects the character of a survey it will not be amiss, before concluding, to mention briefly some interesting new developments in the theory of technical progress.

Until now the level of technology has been treated as exogenous; technical progress was as "manna falling from heaven " (44).

In some recent models, however, the level of technology is treated as an endogenous magnitude. The best known of these models is Arrow's (45). In its original version, fixed coefficients of production were assumed, both ex ante and ex post for each vintage of the capital stock, as well as labour augmenting technical progress (46). If, instead, ex ante substitutability is assumed, the model takes the following form (47):

(43) A demonstration of the theorem of convergence is presented by SHESHINSKI in the framework of his version of the vintage model. KALECKI (op. cit., chapters VIII and IX) describes the process of convergence towards steady growth; in his book, however, the process of convergence takes place with the choice of a constant value of the capital/output ratio in the new vintage of investment goods and with the progressive adjustment of the rate of investment to this value, contrary to how the process of convergence towards steady growth is usually described.

(44) HaHN and MatTeWs, op. cit., p. 836.

(45) K. J. ARRow; The Economic Implications of Learning by Doing, "Review of Economic Studies », June 1962. Kaldor's technical progress function is also based on similar ideas. For this interpretation see HAHN and MATTHEWS, op. cit., p. $847 \mathrm{ff}$.

(46) In a model with fixed production coefficients, labour-augmenting technical progress is characterized by the fact that, as time passes, the capital/labour ratio increases while the capital/output ratio remains unchanged.

(47) See D. Levhurx: Extensions of Arrow's "Learning by Doing ", "Review of Economic Studies », April 1966. 
The ex ante production function is of the [16] type with $A$ equal to $G^{\mathrm{u}}$, where $G$ is the amount of capital up to time $t$ and $u$ is a positive constant less than one.

Vintage $v$ produces an income

$$
Y_{\mathrm{vt}}=F\left(I_{\mathrm{v}}, G_{\mathrm{v}}{ }^{\mathrm{u}} L_{\mathrm{v} t}\right) \text {, }
$$

where $L_{v t}$ is employment with vintage $v$ at time $t$ and $I_{v}=G_{v}$ is gross investment at time $v$, namely

$$
G(v)=G_{v}=\int_{-\infty}^{v} I\left(t^{\prime}\right) d t^{\prime}
$$

To obtain the income produced by the economy as a whole at time $t$ it is necessary to add up the partial incomes $Y_{\mathrm{vt}}$ produced by the different vintages, from $v=t-T(t)$ to $v=t$, where $T(t)$ is the lifetime of capital goods. In the same way we have to proceed for labour. With regard to the ex ante production function, $F(x, y)$, where $x=I_{\mathrm{v}}, y=G_{\mathrm{v}}{ }^{ } L_{\mathrm{v}}$, homogeneity of the first degree ( $F(\lambda x$, $\lambda \bar{y})=\lambda F(x, y))$, and strict convexity $\left(F_{x}, F_{y}>0 ; F_{i x}, F_{y y}<0\right)$ are assumed as usual. Given these assumptions it is possible to find the value of the long-run rate of growth of labour productivity. In the case of steady growth $(Y, I$ and $G$ growing at an identical and constant rate $r$, with labour $L$ growing at a constant rate $n$ ) we have

$$
\alpha=\frac{u}{1-\mathrm{u}} n \text {, }
$$

the rate of growth of labour productivity $\alpha$ is namely proportional to the rate of growth of labour $n$ with a coefficient of proportionality that depends on the value of $u$, the so-called "learning by doing" parameter.

Another way of rendering the level of technology an endogenous magnitude is that followed by Phelps (48). The latter distinguishes one " technological " sector from the whole of the economic system,

(48) See E. S. Phelps: Models of Technical Progress artd the Golden Rulc of Research, "Review of Economic Studies", April 1966. For an extension of Phelps model see S. Gomulka: Extensions of 'The Golden Rule of Research' of Phelps, "Review of Economic Studies n, forthcoming. 
to which to attribute the "production " of technological and organizational innovations. This sector employs $R(t)$ workers and has an $M(t)$ capital stock. The larger $R$ and $M$ are the more will be the researches carried out, the quantity of which will be indicated by $E(t)$ And the more research work is done, the larger will be the quantity of innovations that may be expected and consequently the larger the growth of the level of technology $A$. Thus two production functions exist in the model, the usual production function for goods and services produced outside the technological sector:

$$
Y=F(K, A N)
$$

and a new function referring to the increase in the level of technology:

$$
\dot{A}=H(E(M, R, L), A),
$$

where $L=R+N$ is employment in the economy as a whole. Given the assumptions of linear homogeneity and of convexity of $F, H$ and $E$, it is possible to determine the value of the golden age rate of growth of labour productivity and a variant of the Golden Rule of Accumulation (49).

\section{1. - Conclusions.}

We should like to close with the following remarks:

1) Growth is very often studied by comparing various possible logarithmically parallel golden ages (comparative dynamics). A result of this method that has aroused some interest is the by now well-known "Golden Rule of Accumulation " (50). The peculiar na-

(49) On the Golden Rule see the note below.

(50) The so-called Golden Rule of Accumulation is a typical theorem of comparative dynamics and refers to the determination of the golden age path of growth maximizing consumption. According to the Golden Rule the property characterizing this path is that the net rate of return on capital is equal to the rate of growth. For the Golden Rule of Accumulation in monosectoral models, see in particular E. S. PHelps: The Golden Rule of Accumulation: A Fable for Growthmen, "American Economic Review", September 1961 and Second Fssay on the Golden Rule of Accumulation, "American Economic Review", September 1965; C. C. VoN Weizsäcksæ: 
ture of labour-augmenting technical progress - the only one, as has been seen, that allows the possibility of existence of a continuum of logarithmically parallel golden ages - causes us to view with some scepticismi the results reached in this way, and particularly the Golden Rule.

2) An interesting result contained in Solow's article of 1956 (51) refers to the independence of the long-run rate of growth from the level of the rate of saving and to the necessary convergence of the actual rate of growth towards the "natural " rate once full employment has been ensured. In the terms in which it is obtained by Solow, this result is only possible if labour-augmenting (Harrod's neutral) progress is assumed. The independence of the long-run rate of growth from the level of the aggregate rate of saving seems, moroever, to be confirmed by the research carried out by us in the Appendix, in the framework of a model characterized by the constancy of the elasticity of substitution (i.e. by the assumption of a C.E.S. production function). The results of this research, given in Table II, show clearly this independence. If, however, we take into account the fact that, in reality, the ease with which the factors can be substituted in production (as expressed by the elasticity of substitution) logically varies according to the proportions in which the factors are combined and with time, as well as the fact that the bias of technical progress is bound to change at the different levels of the capital/labour ratio, this conclusion must be viewed with some scepticism. Just as we cannot but view with scepticism the use, which has become increasingly frequent in the theory of growth, of aggregate production functions with technical progress that is factor augmenting in its various specifications. As we have seen, this kind of technical progress refers to a rather particular case.

It must also be pointed out that Kalecki's classification of technical progress, in which the level of the long-run rate of growth is related to the capital intensity of production, is of considerable

W'achstum, Zins und Optimale Investitionsquote, Basel 1962; MEADE: A Neoclassical Theory of Economic Growth, 2nd. ed., London 1962, pp. 110-113; T. W. SWAN: Growth Models of Colden Ages and Production Functions, in Economic Development with Spccial Reference to East Asia, edited by K. E. Berril, London, 1903.

(51) See footnote (11). 
heuristic value for an understanding of the kind of relations ex. isting between technical progress, rate of investment and growth

3) As far as the process of long-run growth is concerned, the conclusion can be reached that, with a given bias of technical progress, this process is apt to be more favourable the more easily factors are substitutable in production and, with a given factor substitutability, the more accentuated is the labour-saving bias (in Hicks' sense). Even if it is rather obvious, this conclusion seems to us to be of some interest. 


\section{APPENDIX I}

\section{Technical Progress and Asymptotic Rates of Growth in the Case of a C.E.S.} Production Function.

1. As is well known, a C.E.S. production function is charaterized by the following properties (52):

1) The value of the elasticity of substitution depends neither on time nor on the value of the capital/labour ratio and is therefore a constant.

2) The function is homogeneous as regards $K$ and $L$; the order of homogeneity of the function (or total elasticity of income with respect to factors), which we can denote with $v$, is constant through time.

It can be demonstrated that these three properties are verified if, and only if, the function can be written as follows:

$$
Y=F(K, L ; t)=\left[a(t) K^{-\xi}+(1-a(t)) L^{-\xi}\right]-v / \xi A(t),
$$

where $\xi=\frac{1}{\sigma}-1, A(t)$ is an increasing function of time and $a(t)$ is the so-called "degree of capital intensity", wher $0 \leq a(t) \leq 1$. The production function with fixed coefficients (of the Leontievan type) and the CobbDouglas production function are particular cases of [1.1]; the former is obtained when $v=1, \sigma=0$, the latter when $v=1, \sigma=1$.

2. Knowledge of the analytical form of the C.E.S. allows us to specify the conditions by which, for $\sigma \neq 1$, we have ncutral technical progress in Harrod's sense. Harrod's neutrality occurs when, $m \equiv K / Y$ being constant, the partial derivalive $F_{K}(K, L ; t)$ remains constant through time. From [1.1] we have, for $v=1$ (from now on only this case will be considered),

$$
F_{\mathrm{K}}=a A^{-\xi}\left(\frac{Y}{K}\right)^{1+\xi}
$$

Let us take $B$ to denote $a A^{-\xi}$. It follows from [1.2] that technical progress according to Harrod's classification will be:

a) $P^{\circ}$, when $\dot{B}(t)=0$

b) $P^{+}$, when $\dot{B}(t)>0$

c) $P^{-}$, when $\dot{B}(t)<0$.

For $\sigma=1$, that is for $\xi=0$, the function $B(t)$ is constant through time only if $a(t)$ is constant. On the contrary, function $A(t)$ can grow arbitrarily. On the other hand, to havi neutrality of technical progress with $\sigma \neq 1$ the changes of $A(t)$ cannot be arbitrary; they must adjust to the changes of $a(t)$.

(52) See e.g. M. Brown: On the Theory and Measurement of Technological Change, London 1966, p. $43 \mathrm{ff}$. 
For $\sigma<1$, that is for $\xi>0, A^{-5}$ decreases in time and in order to have $B(t)=B(0)$ for an arbitrary $t \cong 0$, function $a(l)$ must increase. But, on the other hand, $a(t) \leq 1$. Since also $\lim _{t=+\infty} B(t)=B(0)=\lim _{t=+\infty} a(t) A(t)-\xi, A(t)$ therefore tends, as it increases, towards an asymptotic value not higher than $B(0)^{+\xi}$. In the case of $A^{+}=B(0)^{+\xi}, \lim _{t=+\infty} \mathrm{a}(t)=1$ and then (frum [1.1]):

$$
\lim _{t=+\infty} Y(t)=\lim _{t=+\infty} F(K, L ; t)=B(0) \xi \lim _{t=+\infty} K(t)
$$

$B(0)^{+\xi}$ is thus the capital coefficient for $t=+\infty$.

For $\sigma>1$, that is for $\xi<0$, function $A(t)$ increases and in order for $B(t)$ to equal $B(0), a(t)$ must decrease. For an arbitrary time $t=0$, however, there must be $a(t) \geq 0$.

Here $A(t)$ increases either towards an asymptotic value or unlimitedly. In the second case $\lim a(t)=0$ and consequently

$$
\lim _{t=+\infty} Y(t)=\lim _{t=+\infty} A(t) L(t) .
$$

3. In the case of biased technical progress, $\dot{B}(t): /: 0$. Since $B=a A-\xi, \dot{B}=$ $=\left(\frac{\dot{a}}{a}-\xi \frac{\dot{A}}{A}\right)$ that is $\dot{B} \neq 0$ when

$$
\frac{\ddot{a}}{a}-\xi \frac{\dot{A}}{A}-\not 0
$$

where $A=0$ and $0 \leq a \leq 1$. To get $P^{\prime}$ the ratc of growth of function $a(t)$ must exceed $\xi \frac{\dot{A}}{A}$. Taking into account the constraint represented by the maximum value of $a(t)$, this case can occur first of all for $\xi<0$ (that is for $\sigma>1$ ). For $\xi>0$ (namely for $\sigma<1$ ) technical progress $P^{-}$is more likely, with $\xi \frac{\dot{A}}{A}>\frac{\dot{a}}{a}$. In this case $a(t)$ may be constant and the rate of growth of function $A(t)$ arbitrary (we then have $P_{\mathrm{P}_{\mathrm{A}}}$ ).

4. We shall now try to determine in which way the asymptotic values of income and capital growth rates depend on the paramutior $\sigma$ and on the bias of technical progress.

We shall take $r^{+}$and $h^{+}$to denote these rates The asymptotic values of the other magnitudes are also indicated by placing the plus sign above to the right. For an arbitrary time $t$ the rate of growth of income is determined by the following relation (equation [9] in the text):

$$
\because=U h+Q n+y \text {, }
$$

whore $U-Q=v=-1$ and $n$ ir a'sumed to be constant From [1.1] we can calcliaic coefïicionts $U$ ind $O$ and $y$.

$$
\because:: a\left(\frac{Y}{A K}\right)^{\xi}
$$




$$
\begin{aligned}
& Q=(1-a)\left(\frac{Y}{A L}\right)^{\xi} ; \\
& y=\frac{1}{\xi} \frac{\dot{a}}{a}\left[\left(\frac{Y}{A L}\right)^{\xi}-1\right]+\frac{\dot{A}}{A} .
\end{aligned}
$$

If, as we suppose, $\frac{\dot{K}}{Y} \equiv s$ is constant, we alsc have that

$$
r=h+\frac{\dot{h}}{h} \text {. }
$$

The set of equations [1.6] - [1.10] allows us to find $r(t)$ and $h(t)$ for any $t>0$, where the parameters are the initial conditions, functions $a(t)$ and $A(t)$, and $\sigma$ and $n$.

Case $\xi=0$, that is $\sigma=1$. In this case $U=a, Q=1-a$ and $y=$ $=\frac{\dot{a}}{a} \ln \frac{Y}{A \cdot L}+\frac{\dot{A}}{A}$.

If technical progress is neutral, function $a(t)$ is constant and as a result $h(t)$ satisfies the following equation:

where $\delta=\frac{\dot{A}}{A}$. If $a=1, h$ grows at the rate $\delta$, i.e. $h^{+}=\propto$ and $r^{+}=$

$$
(1-a) h+\frac{\dot{h}}{h}=(1-a) n+\delta
$$
$=h^{+}+\delta^{+}=\infty$.

For $0<a<1$ we have $h^{+}=r^{+}=n \frac{1}{1-a^{+}} \delta^{+}$. If $a(t)$ is an increasing function of time (bias $P^{+}$), where $a^{+}<1$, then $h^{+}=r^{+}=n \frac{1}{1-a^{+}} \delta^{+}$; similarly with bias $P^{\circ}$. An identical result is reached when $a(t)$ decreases through time (bias $P^{-}$).

Case $\xi>0$, that is $\sigma<1$. Since $\dot{B}=a A^{-}-\xi$, [1.7] and [1.9] can be written respectively as follows: $U=B\left(\frac{Y}{K}\right)^{\stackrel{\xi}{a}}$ and $Q=\frac{1-a}{a} B\left(\frac{Y}{L}\right)^{\xi}$. We know that neither $U$ nor $Q$ can have a negative value and that $U+Q=1$.

In the case of Harrod neutrality, the coefficient $B$ is constant. We must therefore have $r^{+} \leq h^{+}$and $r^{+} \leq n$. Since in this case (see [1.9]) we have $\delta^{+}=0$ and $y^{+}=0,[1.6]$ and [1.10] are satisfied for $t=+\infty$ in the case of $r^{+}=h^{+}=n$ (hereafter we exclude the $a^{+}=0$ and $a^{+}=1$ cases, so that we shall always have $y^{+}=\delta^{+}$).

In the case of bias $P^{+}$we have $\dot{B}>0$. In relation to the two abovementioned properties of functions $U(t)$ and $Q(t)$ we must have $r^{+} \leq h^{+}$and $r^{+} \leq n$. Here $\delta^{+}$and $y^{+}$are zero. So that $r^{+}=h^{+}=n$. Lastly, when $\dot{B}<0$ (bias $P^{-}$), $\delta^{+}$may be positive and as a result $r^{+} \leq \delta^{+}+h^{+}$and $r^{+} \leq \delta^{+}+n$. Since $y^{+}=\delta^{+}[1.6]$ may easily be satisfied by such conditions if $r^{+}=n+\delta^{+}$ and $h^{+}=n+\delta^{+}$. In this case $U^{\cdot}=0$ and $Q^{+}=1$.

Case $\xi<0$, that is $\sigma>1$. By a constant $B$ (bias $\mathrm{P}^{\circ}$ ), we have from [1.7] and [1.8] that $r^{+} \geq h^{+}$and $r^{+} \geq n$. Since $y^{+}=\delta^{+}=0$, we have $r^{+}=h^{+}=n$. 
In case $\dot{B}>0$ (bias $P^{+}$) $\delta^{+}$may be positive. Taking into account the properties of functions $U(t)$ and $Q(t)$, we have that $r^{+} \geq h^{+}+\delta^{+}$and $r^{+} \geq \delta^{+}+n$.

If $\delta^{+}>0$ we have $r^{+}>h^{+}$, that is, $s$ being a constant, $h^{+}=+\infty$ (on the basis of [1.10]) and consequently $r^{r}=+\infty, U^{+}=1$ and $Q^{+}=0$. On the other hand, if $\dot{B}<0$ (bias $P^{-}$) we have $y^{+}=\delta^{+}=0, r^{+} \supseteq h^{+}$and $r^{+} \supseteq n$. Equa. tions [1.6] and [1.10] are satisfied if $r^{+}=h^{+}=n$. In the following table we give the asymptotic rates of growth of capital and income according to the value of $\sigma$ and Harrod's bias of technical progress.

TABLE II. - 1

\begin{tabular}{|c|c|c|c|c|}
\hline$\sigma$ & & $p-$ & $p^{\circ}$ & $p+$ \\
\hline \multirow{2}{*}{$\because>1$} & $r^{+}$ & $n$ & $n$ & $\infty$ \\
\hline & $n+$ & $n$ & $n$ & $\infty$ \\
\hline \multirow{4}{*}{$\therefore=\mathrm{i}$} & \multirow{2}{*}{ t+ } & $\delta^{+}$ & \multirow{2}{*}{$n+\frac{8^{+}}{1-a^{+}}$} & $8+$ \\
\hline & & $n+1-a^{+}$ & & n $1-a^{+}$ \\
\hline & \multirow{2}{*}{$h+$} & $8^{+}$ & 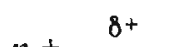 & \multirow{2}{*}{$n+\frac{8+}{1-a+}$} \\
\hline & & $1-a^{+}$ & $1-a^{+}$ & \\
\hline \multirow{2}{*}{$\sigma<1$} & $r+$ & $n+8+$ & $n$ & $n$ \\
\hline & $h^{+}$ & $n+8+$ & $n$ & $n$ \\
\hline
\end{tabular}

5. Using the set of cquations [1.6] - [1.10] we now obtain a similar table, taking into consideration Hicks' classification. The nature of technical progress according to this classification is denoted by the sign of the time partial derivative of the rate of substitution $S=F_{\mathrm{L}} / F_{\mathrm{X}}$.

The value of $F_{\mathrm{K}}$ is given by [1.2]; from [1.1] we have that $F_{L}=(1-a)$ $A\left(\frac{Y}{A L}\right)^{1+\xi}$ that is

$$
S=\frac{1-a}{a}\left(\frac{K}{L}\right)^{1+\bar{\xi}}
$$

If the $K / L$ ratio is constant, the marginal rate of substitution changes only if the quotient $\frac{1-a}{a}$ changes. In Hicks' sense, therefore, technical progress is:

$P^{-}$, if $a(t)$ decreases.

$P^{\circ}$, if $a(t)$ is constant,

$p^{+}$, if $a(t)$ increases, for $t \geqslant 0$.

Unlike in the case if Harrod's classufication, function $A(t)$ has no influence on the bias of technical progress. To simplify matters, let us make two 
assumptions: a) function $A(t)$ increases at a constant positive rate $\delta ; b)$ the asymptotic value of $a(t)$ is positive and less than the unit (53). It is easy to see that case $\xi=0$ (that is $\sigma=1$ ) is the same as by Harrod's classification. For $\xi>0$, that is for $\sigma<1$, we get from equations [1.7] and [1.8] that $U^{+}=0, r^{+}=n+\delta$ and $h^{+}=n+\delta$. On the other hand, for $\xi<0$ (that is $\sigma>1$ ) we get that $U^{+}=1, r^{+}=h^{+}+\delta$. As a result, taking into account [1.10], $r^{+}=\infty$ and $h^{+}=+\infty$.

TABLE II. -2.

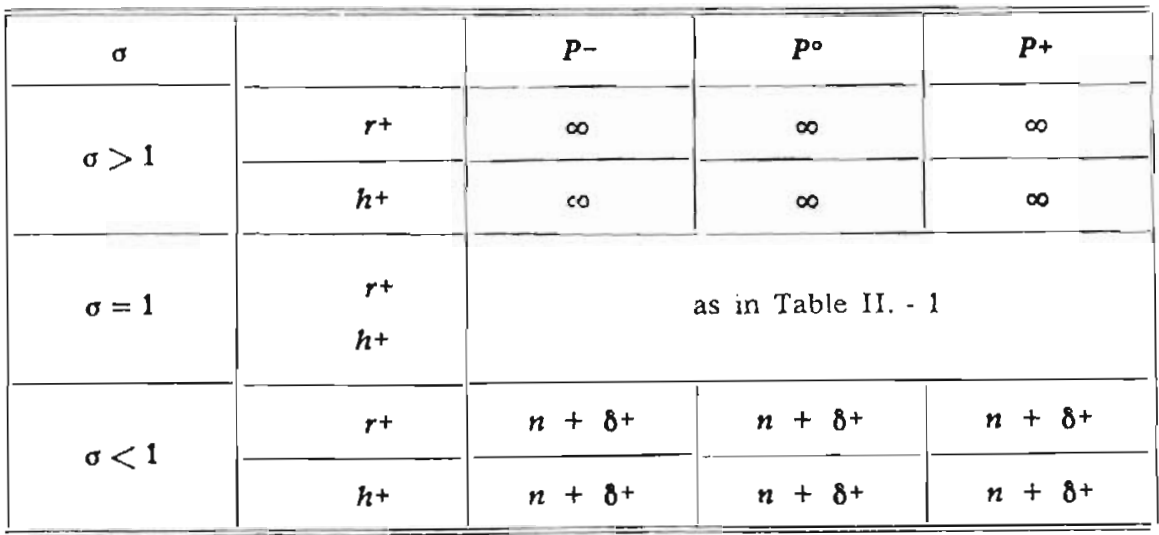

APPENDIX II

\section{Comparison of Hicks' and Harrod's Classifications - Derivation of Results Contained in Table I.}

Since the production function $Y=F(K, L, t)$ is homogeneous of the first degree with respect to $K$ and $L$, the marginal rate of substitution, $S=F_{\mathrm{L}} / F_{\mathrm{K}}$, is a function of $k=K / L$ and $t$; namely $S=(S(k, t)$. So that

Therefore:

$$
d S=\left(\frac{\partial S}{\partial k}\right)_{\mathrm{t}} d k+\left(\frac{\partial S}{\partial t}\right)_{\mathrm{k}} d t
$$

$\frac{\dot{S}}{S}=\frac{k}{S}\left(\frac{\partial S}{\partial k}\right)_{t} \frac{\dot{k}}{k}+\frac{1}{S}\left(\frac{\partial S}{\partial t}\right)_{\mathrm{k}}=-\frac{1}{\sigma} \frac{\dot{k}}{k}+\frac{1}{S}\left(\frac{\partial S}{\partial t}\right)_{\mathrm{k}}$,

where in general $\sigma=\sigma(k, t)$. Moroever $S=F_{L} / F_{\kappa}=k \frac{Q}{U}$ that is

$$
\frac{\dot{S}}{S}=\frac{\dot{k}}{k}+\frac{\dot{Q}}{Q}-\frac{\dot{U}}{U}=\frac{\dot{k}}{k}+\frac{\dot{Q}}{Q}\left(1+\frac{Q}{1-Q}\right) \text {. }
$$

(53) In case $a^{+}=0$ or $a^{+}=1$ what is important is the way in which $a(t)$ tends towards one of these values to determine the magnitude of the asymptotic rate of groth of income and of capital. 
Comparing [2.1] with [2,2] we get as result that

$$
\frac{\dot{Q}}{Q}=(1-Q)\left[\frac{1-\sigma}{\sigma} \frac{\dot{k}}{k}+\frac{1}{S}\left(\frac{\partial S}{\partial t}\right)_{k}\right]
$$

or

$$
\frac{\dot{U}}{U}=(1-U)\left[\frac{\sigma-1}{\sigma}-\frac{\dot{k}}{k}-\frac{1}{S}\left(\begin{array}{l}
\partial S \\
\partial t^{-}
\end{array}\right)_{k}\right] .
$$

In conformity' with Hicks' classification of technical progress, when

$$
\frac{1}{S}\left(\frac{\partial S}{\partial t}\right)_{k} \begin{cases}<0 & \text { - we have } p^{+} \\ =0 & \text { - we have } p^{\circ} \\ >0 & \text { - we have } \mathrm{P}^{-}\end{cases}
$$

When, therefore, we have Hicks' $P^{+}$and $\sigma(t)>1$, it follows from [2.4] that for a given $m$ (then $\dot{k} / k>0$ ) $U$ is positive, i.e. technical progress is $P^{*}$ also for Harrod. We also find conformity of the bias of technical progress in both Hicks' and Harrod's sense for $\sigma(t)=1$ with reference to all three biases of technical progress and for $\sigma(t)<1$ with reference to Hicks' $P^{-}$. But in case $\sigma(t)<1$ and Hicks' $P^{+}$and $\sigma(t)>1$ and Hicks' $P^{-}$all three biases of technical progress in Harrod's sense are possible. We have seen in this way which bias of technical progress in Harrod's sense corresponds to a given bias in Hicks' sense. To see which bias in Hicks' sense corresponds to a given bias in Harrod's sense, i.e. to carry out the same inquiry starting from Harrod's classification instead of from Hicks', all we need to do is to solve [2.4] in relation to $\left(\frac{\partial S}{\partial t}\right)_{k}$ finding in this way the results contained
in table $x$.

\section{2.- - Derivation of [15].}

Since $k=m w(m, t), S=S(k, t)$ is a function also of $m$ and $t$. Calculating the partial derivatives of $S$ with respect to $m$ and $t$, after some calculations we get:

$$
\frac{\dot{S}}{S}=\frac{1}{\sigma}\left(1+\frac{\partial m}{\partial w} \frac{w}{m}\right) \frac{\dot{m}}{m}+\frac{1}{S} \frac{\partial S}{\partial t} .
$$

Moroever $S=m w \frac{\dot{Q}}{U}$ and therefore $\frac{\dot{S}}{S}=\frac{\dot{m}}{m}+\frac{\dot{w}}{w}-\frac{\dot{U}}{(1-U) U}$ further $\frac{1}{S}\left(\frac{\partial S}{\partial t}\right)_{m}=\frac{1}{w}\left(\frac{\partial w}{\partial t}\right)_{m}-\frac{1}{(1-U) U}\left(\frac{\partial U}{\partial t}\right)_{m}$. Taking into account these retations and equation [2.5] we get as result

$$
\frac{\dot{U}}{U}=\frac{\sigma-1}{\sigma}(1-U)\left(1+\frac{m}{w} \frac{\partial w}{d m}\right) \frac{\dot{m}}{m}+\frac{1}{U} \frac{\delta U}{\partial t} \text {. }
$$


From paragraph 6 of this article we have however that $\frac{m}{w} \frac{\partial w}{\partial m}=q=$ $=\frac{U}{1-U}$ (see footnote (28)). Moroever, in brackets, on the right side of [2.0], we have the expression $1+q=\frac{1}{1-U}$. Substituting in [2.6] we get [15].

\section{APPENDIX $I I I$}

Alternative Demonstration of the Correspondence between Harrod's and Kalecki's Classifications.

Fig. 2 shows the relation between the $Y / K \equiv y$ ratio and the quantity of capital $K=x$, given the level of employment $L$ at time $t_{1}$ and at time $t_{1}>t_{1}$. On curve $t_{1}$ point $\mathrm{A}$ is fixed, while point $\mathrm{C}$ is mobile (arbitrary). Points $A$ and $B$ have the same ordinate as have points $C$ and $D$.

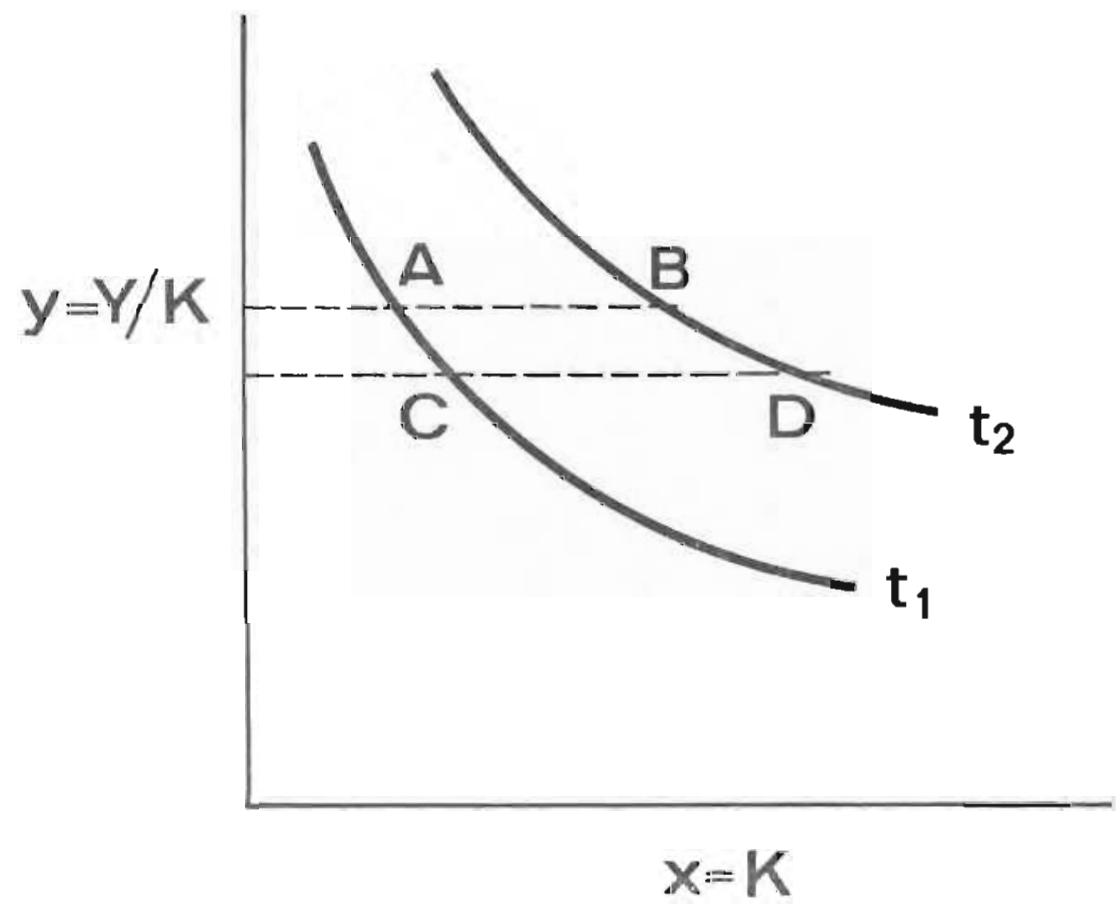

Fig. 2

With 》 we clenote the elasticity of curve $y=y(x, t)$, i.e.

$$
\eta=\frac{x}{y} \frac{\partial y\left(x, t_{)}\right.}{\partial x}=\frac{x}{y} y^{\prime}
$$

In gencral $\eta$ is a function of $x, y$, and $t$; but since $x$ is a function of $y$ and $t$, then $\eta=\eta(y, t)$. We observe that $\eta=\frac{x}{y} y^{\prime}=\frac{K^{2}}{Y}\left(\frac{1}{K} Y_{\mathrm{K}}-\frac{1}{K^{2}} Y\right)=$ $=\frac{K}{Y}\left(F_{\mathrm{B}}-1.\right)$ 
Hence rechnicai progress for Harrod is

a) $p^{+}$if $\frac{\partial \eta}{\partial t}>0$,

b) $P^{-}$if $\frac{\partial \eta}{\partial t} \because 0$,

c) $p^{\circ}$ if $\frac{\hat{c} \eta}{\partial t}=0$.

From [3.i] it follows that for $t=$ constant

$$
\frac{d y}{y \eta(y, t)}=\frac{d x}{x} .
$$

We integrate [3.2] along curve $t_{1}$ from point $A$ to point $C$ and along curve $t_{2}$ from point $\mathrm{B}$ to point $\mathrm{D}$. Correspondingly we get

$$
\begin{aligned}
& \int_{A}^{C} \frac{d y}{y \eta\left(y, t_{1}\right)}=\ln \frac{x_{C}}{x_{\mathrm{A}}} ; \\
& \int_{B}^{D} \frac{d y}{y \eta\left(y, t_{2}\right)}=\ln \frac{x_{\mathrm{D}}}{x_{\mathrm{B}}} .
\end{aligned}
$$

But il $\left(y, t_{2}\right)=\eta\left(y, t_{1}\right)+\int_{t_{1}}^{t_{2}} \frac{\partial \eta(y, t)}{\partial t} d t=\eta(y, t)+\psi(y)$, where $\psi(y) \geqq 0$

respectively in cases $a$ ), b) and $c$ ). Let us subtract equation [3.3] from [3.4]. Since $y_{A}=y_{B}$ and $y_{C}=y_{D}$ the difference of the integrals is equal to the integral of the differences of the integrand functions. We thus get that

$$
\begin{gathered}
\ln \left(\frac{x_{\mathrm{B}}}{x_{\mathrm{A}}} \frac{x_{\mathrm{C}}}{x_{\mathrm{D}}}\right)=\int_{y_{\mathrm{A}}}^{y_{\mathrm{B}}} \frac{d y}{y}\left[\frac{1}{\eta\left(y, t_{1}\right)}-\frac{1}{\eta\left(y, t_{1}\right)+\psi(y)}\right]= \\
=\int_{y_{\mathrm{A}}}^{y_{\mathrm{B}}} \frac{\psi(y) d y}{y \eta\left(y, l_{1}\right)\left[\eta\left(y, t_{\mathrm{B}}\right)+\psi(y)\right]} .
\end{gathered}
$$

The sign of the function under integral in [3.5] is the same as for $\psi(y)$ since the product of the elasticities of the two curves is positive for all values of $y$ and for arbitrary $t_{1}$ and $t_{2}$.

Let us now consider case a) when $\psi(y)>0$. Let us assume that $y_{c}<y_{A}$, as in fig. 2. If the function under integral is positive and the upper limit of integration is inferior to the lower limit, the value of the integral is negative and decreases as $y_{c}$ decreases (i.e. as capital coefficient $m_{\mathrm{c}}=1 / y_{\mathrm{c}}$ increases).

In relation to this, the product $\frac{x_{B}}{x_{A}} \cdot \frac{x_{C}}{x_{D}}$, equal to the ratio between the the rate of growth of capital with $y=y_{\mathrm{A}}$ and the rate of growth of capital 
with $y=y_{c}$ is less than one as $y_{c}$ decreases. Therefore when the capital coefficient $m_{\mathrm{c}}=1 / y_{\mathrm{c}}$ increases in case a) the rates of growth of capital and of income, and consequently the rate of growth of labour productivity, increase.

In the same way it is possible to show that in case b) all these rates of growth decrease as coefficient $m_{c}$ increases and that in case $c$ ) they remain unchanged. Technical progress in therefore $P^{+}, P^{-}$or $P^{\circ}$ also for Kalecki.

With refurence to [3.5] it is possible to reason in the same way, starting from Kalecki's classification. Let us suppose for instance that technical progress is $P^{+}$in Kalecki's sense. For the rate of growth of labour productivity to increase as the capitai coefficient increases, the rate of growth of income must increase too and so must the rate of capital accumulation. For a given $y_{A}$, when $y_{\mathrm{C}}$ decreases the product $\frac{x_{\mathrm{B}}}{x_{\mathrm{A}}} \frac{x_{\mathrm{C}}}{x_{0}}$ must decrease and so $\ln \left(\frac{x_{\mathrm{B}}}{x_{A}} \frac{x_{C}}{x_{D}}\right)$ must decrease. The derivative of the right-hand side of [3.5] with respect to $y_{c}$ is therefore positive (in calculating the derivative we here suppose $d y_{c}<0$ ). 'This derivative, which is equal to the integrand, is positive for arbitrarily chosen values of $y_{C}<y_{A}$ when, and only when $\psi\left(y_{C}\right)>0$, namely when $\frac{\partial \eta\left(y_{c}, t\right)}{\partial t} ; 0$; this proves our thesis in the case we have just examined. It is possible to proceed in the same way in the two remaining cases. 